\title{
Imbibition capillary pressure and relative permeability of mixed-wet microporous rock: new insights from history matching
}

\author{
Yukie Tanino • Magali Christensen
}

Received: date / Accepted: date

\begin{abstract}
We use a Darcy-scale simulator to extract residual oil saturation, forced imbibition capillary pressure, and relative permeability by history matching to measured pressure drop and cumulative oil production during multi-speed centrifuge experiments and constant-rate waterfloods in Indiana limestone cores under four different wettability states established by adding different naphthenic acids to the oil phase. Residual oil saturation decreases monotonically as advancing bulk contact angle increases from $\theta_{\mathrm{a}}=110^{\circ}$ to $150^{\circ}$, in sharp contrast to the nonmonotonic dependence displayed by the core-averaged oil saturation which are often mis-interpreted to be representative of true residual saturation. The magnitude of the capillary pressure required to establish a particular water saturation increases with $\theta_{\mathrm{a}}$. Saturation-normalized water relative permeability exceeds one at $\theta_{\mathrm{a}} \geq 125^{\circ}$, with equivalent slip lengths of up to $O(200) \mathrm{nm}$. The simulations indicate that capillary end effects may be significant during displacement experiments under typical laboratory conditions, even in mixed-wet media of relatively low permeability, and highlight the importance of using numerical simulation to interpret displacement experiments under capillary-dominated conditions.
\end{abstract}

Keywords capillary trapping · multiphase flow · slippage · residual saturation · history matching

\section{Introduction}

Capillary-hydraulic properties of an incompressible, laminar flow of immiscible liquid pairs through an isotropic, homogeneous porous medium are characterized

In a conference paper prepared for presentation at the International Symposium of the Society of Core Analysts held in Trondheim, Norway, 27-30 Aug. 2018 (Christensen and Tanino, 2018), we present the equilibrium analysis of the centrifuge experiments and a preliminary interpretation of a subset of the waterfloods as those considered in the present paper optimizing only relative permeability parameters.

Y. Tanino

School of Engineering, University of Aberdeen

Tel.: +44 (0)1224274514

E-mail: ytanino@abdn.ac.uk 


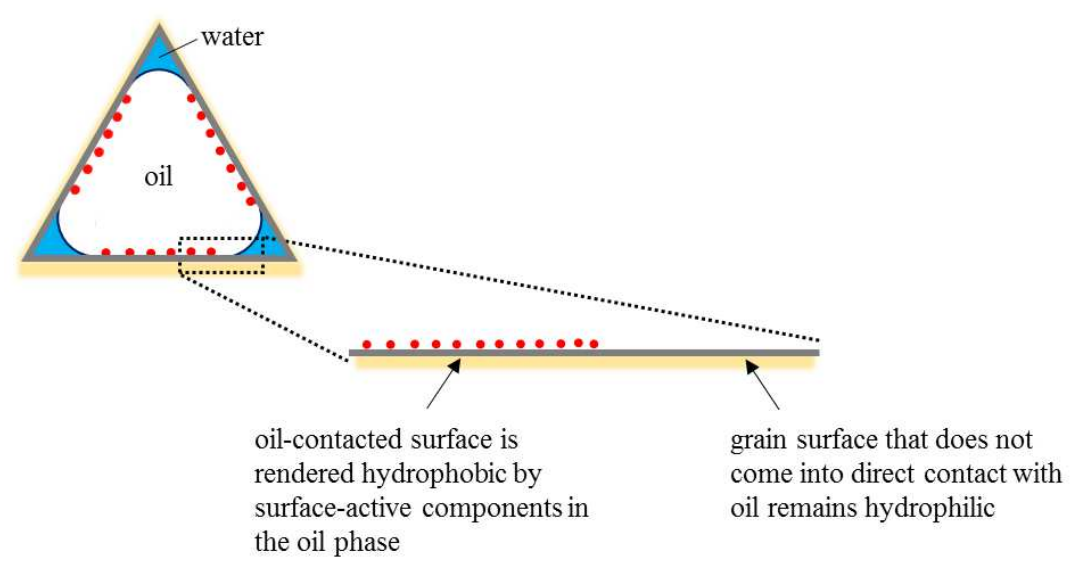

Fig. 1 A mechanism for mixed wettability proposed by Salathiel (1973); Kovscek et al (1993). Cross-section of a single pore that has been invaded by oil during primary drainage. Adapted from Morrow and Mason 2001; Valvatne and Blunt 2004.

by three properties. The first two are the permeabilities of the porous medium to the two liquids,

$$
k_{\mathrm{j}}=\mu_{\mathrm{j}} u_{\mathrm{j}}\left(\frac{\mathrm{d} p_{\mathrm{j}}}{\mathrm{d} x}\right)^{-1},
$$

where $\left(\mu_{\mathrm{j}}, u_{\mathrm{j}}, p_{\mathrm{j}}\right)$ are the dynamic viscosity, volumetric flow rate per unit bulk cross-sectional area, and the pressure of phase $\mathrm{j}$, respectively, and $x$ is the direction of mean flow. In this paper we restrict our discussion to liquid pairs comprising an aqueous phase $(\mathrm{j}=\mathrm{w})$ and an oleic phase $(\mathrm{j}=\mathrm{o})$. The third property is the equilibrium saturation that results from a given capillary pressure,

$$
p_{\mathrm{c}}=p_{\mathrm{o}}-p_{\mathrm{w}} .
$$

It is well established that $k_{\mathrm{w}}, k_{\mathrm{O}}$, and $p_{\mathrm{c}}$ are functions of both saturation and saturation history (Bear, 1988) and a number of empirical models have been proposed to describe them (e.g., Brooks and Corey, 1964; Skjaeveland et al, 2000; Lomeland et al, 2005; Duchenne et al, 2015; Honarpour et al, 1982). For imbibition, which we define in this paper as increasing water saturation, $S_{\mathrm{w}}$, irrespective of whether or not the porous medium is hydrophilic, all models assume water is immobile when the fractional volume of the pore space that it occupies falls below the irreducible water saturation, $S_{\mathrm{w}}=S_{\mathrm{wi}}(>0)$, or above $S_{\mathrm{w}}=1-S_{\text {or }}(<1)$, where $S_{\text {or }}$ is the residual oil saturation. This paper considers the dependence of these constitutive relationships on contact angle, focusing specifically on mixedwet conditions.

A porous medium is said to be mixed-wet if the hydrophilicity of the grain surface, as characterized by the local contact angle, varies at the pore-scale and the sub-pore scale. In initially water-saturated porous media that are subsequently invaded by non-aqueous phase liquids (NAPL), such as is the case in NAPLcontaminated groundwater aquifers (e.g., Dwarakanath et al, 2002; Powers and Tamblin, 1995; Powers et al, 1996) and petroleum reservoirs (e.g., Wood et al, 1991; Jerauld and Rathmell, 1997; Øren et al, 1998), surface-active components 
render parts of the grain surface that come into direct contact with the NAPL hydrophobic (oil-wetting) while the rest of the grain surface remains hydrophilic (water-wetting). These pristine surfaces may be grain surfaces surrounding pores that are not invaded by oil (e.g., Alhammadi et al, 2017; AlRatrout et al, 2018) or corners and grooves of oil-invaded pores (e.g., Fig. 1). Moreover, recent studies suggest that mixed wettability may be a salient and intrinsic feature of carbonate rock: contact angles larger than $90^{\circ}{ }^{1}$ were measured in quarried limestone (AlRatrout et al, 2017) and oil-wet patches were identified in chalk (Hassenkam et al, 2009) that had never been exposed to oil.

In this paper we focus on naturally hydrophilic rock that are rendered mixedwet by differential adsorption of napthenic acids in the oil phase during primary drainage. The wettability of such systems is typically characterized by that of the oil-contacted grain surfaces which, in turn, are characterized by the bulk contact angle that the oil/water interface makes on a mineralogically representative, flat substrate that has been exposed to the test oil ('aged') under matching temperature and pressure. Carbonate rock in particular is relatively pure (e.g., Tanino and Blunt, 2013; Gharbi and Blunt, 2012) and is well represented by calcite.

In situ contact angle is a function of local grain roughness, local flow velocity, confinement, and local pore geometry in addition to the composition of the rock, oil, and the brine, and takes on a wide distribution even within a mineralogically uniform rock (AlRatrout et al, 2017) or packed beds of spheres. Notwithstanding this, bulk contact angles on a flat, systematically polished, mineralogically pure substrate are a convenient proxy for changes to wettability in response to changes in oil/brine/mineral chemistry. Physical reasoning suggests that there should be a strong, positive correlation between between the mean in situ contact angle and the bulk contact angle; experimental evidence was reported recently for a crude oil-aged reservoir carbonate rock (AlRatrout et al, 2018). ${ }^{2}$

Laboratory studies systematically investigating the impact of contact angle on capillary-hydraulic properties are limited, particularly under well-defined mixedwet conditions. In particular, the contact angle dependence of $S_{\text {or }}$ remains a subject of controversy for two reasons. First, only limited data are available in the literature under unambiguous and well-characterized mixed-wet conditions (see, e.g., Tanino et al, 2015; Humphry et al, 2013, for discussion). Second, the interpretation of laboratory data is made difficult by capillary end effects, which can result in oil saturations at the end of displacement experiments that are significantly larger than the "true" $S_{\text {or }}$.

While some laboratory studies and pore network simulators report the dependence of oil recovery on contact angle, their findings are contradictory, with minimum core-averaged remaining oil saturation after a fixed pore volumes (pv)

\footnotetext{
1 In this paper, all contact angles are defined through the aqueous phase.

2 One could characterize a mixed wet oil/brine/rock system using two contact angles instead of one: one angle representing the oil-contacted grain surface and one angle representing a surface that remains in contact with bulk water (cf. Fig. 1). The challenge in this approach lies in the contact angle measurement on the latter: it is not practical to measure the contact angle on a pristine surface using the test oil of interest, since exposure to its constituents will alter the wettability of the surface during the measurement. One way to circumvent this challenge is to measure the contact angle using a gas (e.g., air) or a synthetic oil free of surface-active components (e.g., $n$-decane) as the non-aqueous phase (e.g., Liu and Buckley, 1997; Wu et al, 2008). However, this approach has the disadvantage that the measured contact angle is not directly related to in situ values in the oil/brine/rock system of interest.
} 
(ranging from 2.4 to $100 \mathrm{pv}$ ) of water injected reported near neutral wettability in some studies (Kennedy et al, 1955; Morrow et al, 1973; Jadhunandan and Morrow, 1995; Amott, 1959), under moderately oil-wet conditions (Christensen and Tanino, 2017b), and under strongly oil-wet conditions in others (Owens and Archer, 1971). Core-averaged oil saturation established by centrifuge has also been observed to display a minimum at near-neutral wettability (Chen et al 2006; Lorentz et al 1974 as cited in Anderson 1987). Similarly, some pore network simulations (Ryazanov et al, 2009, 2010) suggest that minimum $S_{\text {or }}$ occurs under strongly oil-wet conditions, while others predict that $S_{\text {or }}$ is independent of contact angle once the system is oil-wetting (Anggraini, 2013), which is also plausible.

This paper presents forced imbibition $S_{\mathrm{w}}\left(p_{\mathrm{c}}\right)$ and $k_{\mathrm{i}}\left(S_{\mathrm{w}}\right)$ correlations derived from transient oil production from mixed-wet Indiana limestone at maximum initial oil saturation measured under multi-speed centrifugal acceleration and under constant-rate waterflood. Indiana limestone is $99.0 \%$ calcite and is naturally water-wetting (Tanino and Blunt, 2013) and, accordingly, its wettability during watertflood/forced imbibition is characterized by the advancing contact angle that a drop of brine makes on a flat calcite substrate submerged in the oil phase, which ranged from $\theta_{\mathrm{a}}=110^{\circ}$ to $150^{\circ}$. The $\theta_{\mathrm{a}}$-dependence of the best-fit relative permeabilities (Sec. 3.1), capillary pressure (Sec. 3.2), and $S_{\text {or }}$ (Sec. 3.3) are discussed. Results are compared with remaining saturation that had not been corrected for capillary end effects.

\section{Method}

We consider three multi-speed centrifuge experiments and 8 waterfloods on 1.5 in.diameter, mixed-wet Indiana limestone (USA) cores. Of the 8 waterfloods, 5 were performed by Christensen and Tanino (2017b), 1 by Christensen and Tanino (2017a), and 1 by Tanino and Blunt (2013). In all experiments, initial oil saturation, $S_{\text {oi }}$, was established using the porous plate method and coreflood apparatus used previously (Christensen and Tanino, 2017b) and the same wettability alteration protocol was employed. Cores remained at ambient temperature and pressure throughout each experiment and were oriented horizontally during all fluid displacements.

\subsection{Rock}

The cores used in the experiments analyzed presently had porosities ranging from $\phi=0.133$ to 0.155 and absolute permeabilities ranging from $k=1.7 \times 10^{-15}$ to $11 \times 10^{-15} \mathrm{~m}^{2}$ (Table S1). Additional $(\phi, k)$ measurements and mercury injection capillary pressure data are presented in Supplementary Materials S1 and S2, respectively. Nuclear magnetic resonance transverse relaxation times of the rock were measured previously (Tanino and Blunt, 2012).

\subsection{Fluids}

An aqueous solution of 5 wt. $\% \mathrm{NaCl}$ and 1 wt. $\% \mathrm{KCl}$ saturated with limestone was used as connate water and imbibing water in both the centrifuge experiments 
Table 1 Selected experimental conditions of waterflood and centrifuge experiments. Experiments starting with ' $\mathrm{C}$ ' are centrifuge experiments. Others are waterfloods by Tanino and Blunt (2013) (TB/I), Christensen and Tanino (2017b) (W, O, V, AD, AH), and Christensen and Tanino $(2017 \mathrm{a})(\mathrm{N})$; coreflood D is unpublished. $\rho_{\mathrm{o}}$ and $\rho_{\mathrm{w}}$ are densities of the oil and brine as measured at the end of primary drainage in each experiment. Additional conditions are presented in Tables S1 and S2.

\begin{tabular}{|c|c|c|c|c|c|c|c|}
\hline $\begin{array}{l}\theta_{\mathrm{a}} \\
{\left[{ }^{\circ}\right]}\end{array}$ & $\begin{array}{c}\sigma \\
{[\mathrm{mN} / \mathrm{m}]}\end{array}$ & core & $S_{\mathrm{oi}}$ & $\begin{array}{c}\rho_{\mathrm{O}} \\
{\left[\mathrm{kg} / \mathrm{m}^{3}\right]}\end{array}$ & $\begin{array}{c}\rho_{\mathrm{w}} \\
{\left[\mathrm{kg} / \mathrm{m}^{3}\right]}\end{array}$ & $\begin{array}{c}U_{\mathrm{w}} \\
{[\mu \mathrm{m} / \mathrm{s}]}\end{array}$ & $\begin{array}{c}\mathrm{Ca} \text { or } \mathrm{Bo} \\
{\left[\times 10^{-7}\right]}\end{array}$ \\
\hline \multirow{3}{*}{$110^{\circ}$} & \multirow{3}{*}{$33.00 \pm 0.07$} & $\mathrm{C} 2$ & 0.919 & 731.0 & 1044.6 & $\mathrm{n} / \mathrm{a}$ & 4.9 to 150 \\
\hline & & $\mathrm{W}$ & 0.884 & 732.4 & 1042.1 & 1.5 & 10 \\
\hline & & D & 0.904 & 732.6 & 1043.2 & 1.5 & 10 \\
\hline \multirow{3}{*}{$125^{\circ}$} & \multirow{3}{*}{$28.41 \pm 0.06$} & C1 & 0.852 & 732.8 & 1045.8 & $\mathrm{n} / \mathrm{a}$ & 2.8 to 85 \\
\hline & & $\mathrm{O}^{3}$ & 0.890 & 732.6 & 1042.6 & 1.5 & 6.7 \\
\hline & & $\mathrm{V}$ & 0.865 & 732.7 & 1042.1 & 3.0 & 12 \\
\hline \multirow{2}{*}{$135^{\circ}$} & \multirow{2}{*}{$23.59 \pm 0.05$} & $\overline{\mathrm{AD}}$ & 0.872 & 733.1 & 1042.1 & 1.5 & 7.4 \\
\hline & & $\mathrm{AH}$ & 0.867 & 732.9 & 1041.9 & 3.0 & 13 \\
\hline \multirow{3}{*}{$150^{\circ}$} & \multirow{3}{*}{$16.46 \pm 0.03$} & C3 & 0.886 & 733.0 & 1043.3 & $\mathrm{n} / \mathrm{a}$ & 1.7 to 52 \\
\hline & & $\mathrm{N}$ & 0.818 & 732.8 & 1042.1 & 1.5 & 7.3 \\
\hline & & $\mathrm{TB} / \mathrm{I}^{4}$ & 0.911 & 732.6 & 1059.0 & 1.5 & 9.2 \\
\hline
\end{tabular}

and the waterfloods (cf. Tanino and Blunt, 2012, 2013; Christensen and Tanino, $2017 \mathrm{~b}, \mathrm{a})$. Its dynamic viscosity is $\mu_{\mathrm{w}}=1.087$ to $1.109 \mathrm{mPa}$ s at typical ambient conditions of $T=21$ to $22^{\circ} \mathrm{C}$ (Romanello, 2015).

Four oils were considered: $66 \mathrm{mM}$ solutions of cyclohexanecarboxylic acid, cyclohexanepropionic acid, cyclohexanebutyric acid (waterflood only), and cyclohexanepentanoic acid in $n$-decane. The interfacial tension of $n$-decane/brine is $\sigma=$ $52.88 \pm 0.08 \mathrm{mN} / \mathrm{m}$; the addition of the acids reduces this value to $\sigma=33.00 \pm 0.07$, $28.41 \pm 0.06,23.59 \pm 0.05$, and $16.46 \pm 0.03 \mathrm{mN} / \mathrm{m}$ in order of increasing alkyl chain length of the acid (Christensen and Tanino, 2017b). Similarly, these acids have been found to render calcite hydrophobic in order of increasing alkyl chain length (Wu et al, 2008; Christensen and Tanino, 2017b). This wettability alteration is characterized by the dynamic contact angle that an expanding drop of brine makes on a flat, polished calcite submerged in the test oil, $\theta_{\mathrm{a}} \cdot \theta_{\mathrm{a}}=54^{\circ} \pm 7^{\circ}$ for pure $n$-decane, but the presence of the acids in the oil phase increases this value to $\theta_{\mathrm{a}}=107^{\circ}, 127^{\circ} \pm 2^{\circ}, 134^{\circ} \pm 2^{\circ}$, and $150^{\circ} \pm 0.6^{\circ}$ in order of increasing alkyl chain length (Christensen and Tanino, 2017b). For conciseness, these angles will be approximated as $\theta_{\mathrm{a}} \approx 55^{\circ}, 110^{\circ}, 125^{\circ}, 135^{\circ}$, and $150^{\circ}$ in this paper. Readers are directed to $\mathrm{Wu}$ et al 2008 for further details on the acid treatment.

The densities of the test oil and brine, $\left(\rho_{\mathrm{o}}, \rho_{\mathrm{w}}\right)$, were measured at $T=20$ or $21^{\circ} \mathrm{C}$ (Anton Paar $4100 \mathrm{M}$ ) at the end of primary drainage prior to waterflood and centrifugation, respectively (Table 1).

\footnotetext{
3 It appears that water in the flow lines imbibed into the core after $S_{\text {oi }}$ was measured but prior to the initiation of the waterflood. At the onset of the waterflood, oil saturation in the core had dropped from $S_{\mathrm{oi}}=0.890$ (Table 1 ) to $\left\langle S_{\mathrm{o}}\right\rangle=0.852$; this is accounted for in the history matching.

4 Only two $\Delta p_{\mathrm{w}}(t)$ measurements are available.
} 
2.3 Establishment of initial oil saturation and mixed wettability

Details of the coreflood apparatus and procedure are reported elsewhere (Christensen and Tanino, 2017a,b; Tanino and Blunt, 2012, 2013) and are thus omitted here. Similarly, the protocol for wettability alteration in carbonate cores are discussed in detail in Christensen and Tanino 2017b and Wu et al 2008. The key steps for establishing $S_{\text {oi }}$ were as follows:

1. Prior to use, all cores were cleaned by Soxhlet extraction using a 50:50 mixture of methanol and toluene, then oven dried under vacuum.

2. Each core was alternately flushed with gaseous $\mathrm{CO}_{2}$ and evacuated over several days to remove air, then flushed with degassed brine to fully saturate it. $k$ was calculated from the pressure drop across the length of the core at three or four different flow rates (cf. Text S1 in Supplementary Materials).

3. The test oil was injected into the core at constant pressure to establish $S_{\text {oi }}=$ 0.82 to 0.92 using the porous plate method (Tanino and Blunt, 2012) (Table 1). Drainage lasted between 32 to 49 days (Table S1); during this time, the naphthenic acid in the oil phase adsorbs onto the grain surface. Bulk contact angle measurements indicate that equilibrium is reached within $50 \mathrm{~h}$ (Christensen and Tanino, 2017b).

4. Once brine production ceased, the core was removed from the Hassler cell and weighed to determine $S_{\text {oi }}$ by mass balance.

The uncertainty in saturation determination by mass balance is estimated to be 0.10\% (Christensen and Tanino, 2017a). Cores were not reused after wettability alteration.

\subsection{Multi-speed centrifuge experiment}

Three cores (C1, C2, C3) were subsequently sent to a commercial laboratory to undergo forced secondary imbibition by centrifuge (Optima L-100 XP Ultracentrifuge, COREX (UK) Ltd, Aberdeen); raw data are available as Supplementary Material. Here, the cores were spun inside a brine-filled sample holder at eight rotational speeds $(\omega=1060,1410,1850,3280,3370,4460,5300$, and $5830 \mathrm{rpm}$ ) in increasing order, resulting in a stepwise draining of oil from each core (Fig. 2, markers). These speeds correspond to Bond numbers

$$
\mathrm{Bo}=\frac{k \omega^{2}\left(\rho_{\mathrm{w}}-\rho_{\mathrm{o}}\right)\left(r_{1}+L / 2\right)}{\sigma\left|\cos \theta_{\mathrm{a}}\right|},
$$

where $r$ is the radial distance from the axis of rotation, $r=r_{1}$ is the coordinate of the end of the core closest to the axis, and $L$ is the length of the core, ranging from $\mathrm{Bo}=(1.7$ to 150$) \times 10^{-7}$; a discussion on the rate dependence of centrifuge-driven imbibition can be found in supplementary material S5. Each $\omega$ was maintained for a period that varied between $36.6 \mathrm{~h}$ and $91 \mathrm{~h}$ (Table S2). The cumulative volume of oil expelled from each core was measured at selected times using a calibrated glass collector.

We analysed the data in two steps. First, we extracted $S_{\mathrm{w}}\left(p_{\mathrm{c}}\right)$ assuming that hydrostatic equilibrium had been reached at each $\omega$ before it was increased, considering only the total volume of oil produced at each $\omega$ ("equilibrium analysis"). 


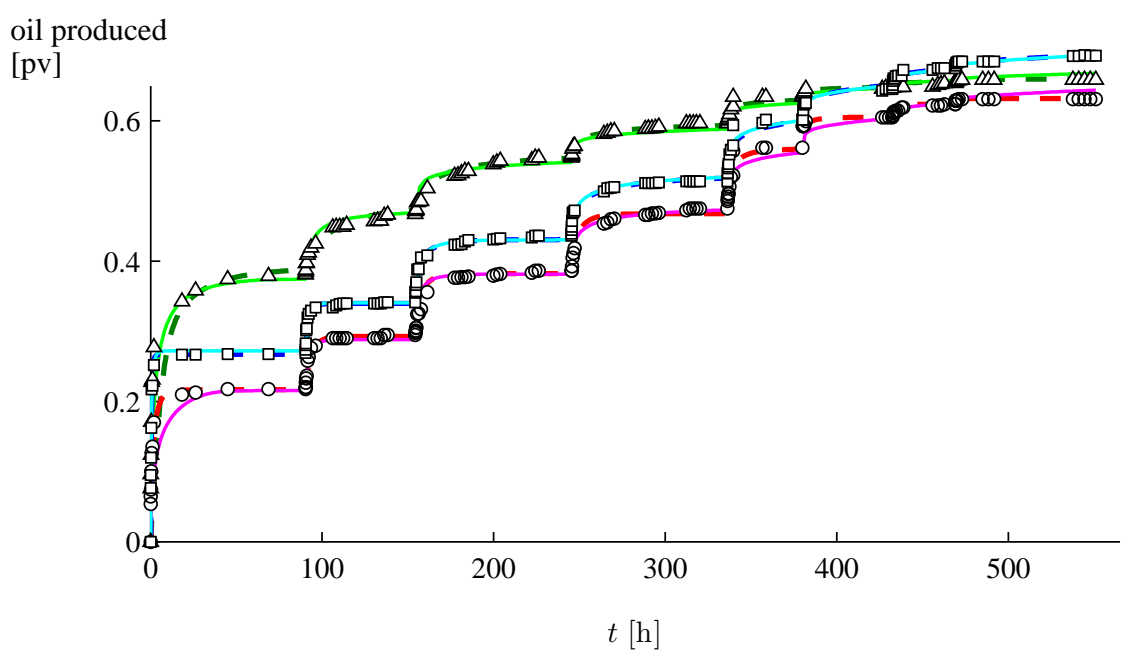

Fig. 2 Cumulative oil production by centrifuge as a function of time for $\theta_{\mathrm{a}}=110^{\circ}(\triangle)$, $125^{\circ}(\bigcirc)$, and $150^{\circ}(\square)$. Markers depict instantaneous measurements. Lines depict simulated production using optimized $p_{\mathrm{c}}\left(S_{\mathrm{w}}\right)$ and $k_{\mathrm{rj}}\left(S_{\mathrm{w}}\right)$, where $k_{\mathrm{rj}}\left(S_{\mathrm{w}}\right)$ was described by Eq. (13) (solid lines) or Eq. (18) (dashed).

Then, we revised our estimate of $S_{\mathrm{w}}\left(p_{\mathrm{c}}\right)$ and extracted $k_{\mathrm{rj}}\left(S_{\mathrm{w}}\right)$ using a numerical simulator and nonlinear least-squares fitting to the complete production data. Each step is described below.

\subsection{1 $S_{w}\left(p_{c}\right)$ estimation assuming equilibrium}

Assuming $p_{\mathrm{c}}=0$ at the end of the core closest to the axis of rotation, the equilibrium capillary pressure distribution within the sample at a particular $\omega$ is given by

$$
p_{\mathrm{c}}(r)=p_{\mathrm{o}}(r)-p_{\mathrm{w}}(r)=-\frac{1}{2}\left(\rho_{\mathrm{w}}-\rho_{\mathrm{o}}\right) \omega^{2}\left(r^{2}-r_{1}^{2}\right),
$$

where $p_{\mathrm{o}}$ and $p_{\mathrm{w}}$ are the cross-sectionally averaged pressure in the oil phase and the brine, respectively. In the present experiments $r_{1}=166.3 \mathrm{~mm}$. From Eq. (4), $p_{\mathrm{c}}(r)$ decreases like $-r^{2}$ and, correspondingly, the cross-sectionally averaged water saturation $S_{\mathrm{w}}$ increases with increasing $r$ in homogeneous samples. Only the coreaveraged saturation at each $\omega$,

$$
\left\langle S_{\mathrm{w}}\right\rangle(\omega)=\frac{1}{L} \int_{r_{1}}^{r_{1}+L} S_{\mathrm{w}}(r, \omega) \mathrm{d} r
$$

can be extracted from each centrifuge experiment. Using Eq. (4) to change variables, Eq. (5) can be written as

$$
\left\langle S_{\mathrm{w}}\right\rangle\left(p_{\mathrm{c}}\right)=-\frac{1}{L} \int_{0}^{p_{\mathrm{c}}\left(r_{1}+L\right)} \frac{R r_{1}}{2 p_{\mathrm{c}}\left(r_{1}+L\right) \sqrt{1-R \frac{p_{\mathrm{c}}\left(r_{1}+L\right)}{p_{\mathrm{c}}(r)}}} S_{\mathrm{w}}\left(p_{\mathrm{c}}\right) \mathrm{d} p_{\mathrm{c}}
$$

where $R=1-\left[\left(r_{1}+L\right) / r_{1}\right]^{2} ; R<0$. 
Many solutions to Eq. (6) have been proposed (see, e.g., Ayappa et al 1989 for an overview). In the present study, we use Forbes (1994)'s solution of the second kind, as implemented in core analysis software CYDAR ${ }^{\mathrm{TM}}$ (CYDAREX), to extract $S_{\mathrm{w}}\left(p_{\mathrm{c}}\right)$ such that the corresponding, recalculated $\left\langle S_{\mathrm{w}}\right\rangle\left(p_{\mathrm{c}}\left(r_{1}+L, \omega\right)\right)$ best fits the measured $\left\langle S_{\mathrm{w}}\right\rangle\left(p_{\mathrm{c}}\left(r_{1}+L, \omega\right)\right)$. The simulations were one dimensional and the boundary condition at $r=r_{1}$ was set to $p_{\mathrm{c}}=0$. The numerical scheme was fully implicit, and 30 uniform grids were used. The optimization imposed that $S_{\mathrm{w}}$ increases monotonically with increasing $\left|p_{\mathrm{c}}\right|$ as recommended by Forbes (1994).

Cores were centrifuged directly from $S_{\text {oi }}$ so we could not measure water saturation established by spontaneous imbibition, i.e., $\left\langle S_{\mathrm{w}}\right\rangle$ at $p_{\mathrm{c}}=0$, on them. Instead, we used $\left\langle S_{\mathrm{w}}\right\rangle\left(p_{\mathrm{c}}=0\right)$ measured independently on the same rock/oil/brine system (but different cores) ${ }^{5}$ :

$$
\left\langle S_{\mathrm{w}}\right\rangle(0)= \begin{cases}0.955 \pm 0.045-(0.479 \pm 0.066) S_{\mathrm{oi}} & \text { if } \theta_{\mathrm{a}}=55^{\circ} \\ 0.229 & \text { if } \theta_{\mathrm{a}}=125^{\circ} \\ 1.0729 \pm 0.05-(0.9619 \pm 0.06) S_{\mathrm{oi}} & \text { if } \theta_{\mathrm{a}}=150^{\circ}\end{cases}
$$

$\left\langle S_{\mathrm{w}}\right\rangle(0)$ was not considered in the analysis of $\theta_{\mathrm{a}}=110^{\circ}$ data due to a lack of suitable measurements.

\subsection{2 $k_{i}\left(S_{w}\right)$ and $p_{c}\left(S_{w}\right)$ determination from transient flow}

Relative permeabilities to oil and brine, which we define as

$$
k_{\mathrm{rj}}=\frac{k_{\mathrm{j}}}{k},
$$

with $\mathrm{j} \in\{\mathrm{w}, \mathrm{o}\}$, and a more accurate estimate of $p_{\mathrm{c}}\left(S_{\mathrm{w}}\right)$ were extracted from the centrifuge data by history matching of simulated oil production to measured values using CYDAR ${ }^{\mathrm{TM}}$ (cf. Fig. 2). As before, the simulations were one-dimensional, the numerical scheme was fully implicit, and fluids were assumed to be incompressible. 98 uniform grid blocks were used to improve accuracy.

Capillary pressure was modelled using the following analytical function (CYDAREX, 2017):

$$
p_{\mathrm{c}}\left(S_{\mathrm{w}}\right)=p_{\mathrm{c}}^{+} \ln \left(1-\widehat{S_{\mathrm{w}}}\right)+p_{\mathrm{c}}\left(S_{\mathrm{wi}}\right),
$$

where

$$
\widehat{S_{\mathrm{w}}}(t)=\frac{S_{\mathrm{w}}(t)-S_{\mathrm{wi}}}{1-S_{\mathrm{or}}-S_{\mathrm{wi}}}
$$

is the rescaled water saturation and $p_{\mathrm{c}}\left(S_{\mathrm{wi}}\right), p_{\mathrm{c}}^{+}$, and $S_{\text {or }}$ were fitted to data. Primary drainage using the porous plate method have shown that water can be drained to near-zero saturations with sufficiently high capillary pressure (e.g., Tanino and Blunt, 2012) and, accordingly, irreducible water saturation was taken to be $S_{\mathrm{wi}}=0$ in all simulations. It follows immediately from Eq. (9) that

$$
\widehat{S_{\mathrm{w}}}(0)=1-\exp \left\{-\frac{p_{\mathrm{c}}\left(S_{\mathrm{wi}}\right)}{p_{\mathrm{c}}^{+}}\right\}
$$

${ }^{5}$ Eq. (7b) is based on $\left\langle S_{\mathrm{w}}\right\rangle(0)$ established from $S_{\text {oi }}=0.90$ (core AK, Table S1). Eqs. (7a) and $(7 \mathrm{c})$ are lines of best-fit to $\left\langle S_{\mathrm{w}}\right\rangle(0)$ measured by Tanino and Blunt (2013). Further details can be found in the Supplementary Materials S4. 
Table 2 Upper and lower bounds for each parameter imposed on the history matching to centrifuge experiments. The parameter range from which $p_{\mathrm{c}}^{+}$and $p_{\mathrm{c}}(0)$ were sampled are sufficiently large such that they had no impact on the optimization.

\begin{tabular}{c|cc|cc|cc}
\hline & \multicolumn{2}{|c|}{$\mathrm{C} 2$} & \multicolumn{2}{c|}{$\mathrm{C} 1$} & \multicolumn{2}{c}{$\mathrm{C} 3$} \\
parameter & $\min$ & $\max$ & $\min$ & $\max$ & $\min$ & $\max$ \\
\hline$p_{\mathrm{c}}^{+}[\mathrm{kPa}]$ & 0 & 500 & 0 & 500 & 0 & 500 \\
$p_{\mathrm{c}}\left(S_{\mathrm{wi}}\right)[\mathrm{kPa}]$ & -500 & 500 & -500 & 500 & -500 & 500 \\
$1-S_{\mathrm{or}}{ }^{2}$ & 0.755 & 1 & 0.814 & 1 & 0.850 & 1 \\
$k_{\mathrm{rw}}\left(S_{\mathrm{or}}\right)^{b}$ & $0.369^{c}$ & $0.798^{c}$ & $0.499^{d}$ & $1.017^{d}$ & $0.629^{e}$ & $1.661^{e}$ \\
$k_{\mathrm{ro}}\left(S_{\mathrm{wi}}\right)$ & 0.898 & 1 & 0.898 & 1 & $0.762^{f}$ & 1 \\
\hline$\alpha_{\mathrm{w}}, \alpha_{\mathrm{o}}$ & 1 & 10 & 1 & 10 & 1 & 10 \\
\hline$L_{\mathrm{w}}, L_{\mathrm{O}}$ & 1 & 10 & 1 & 10 & 1 & 10 \\
$E_{\mathrm{w}}$ & 1 & 50 & 1 & 50 & 0.01 & 50 \\
$E_{\mathrm{O}}$ & 1 & 100 & 1 & 100 & 1 & 100 \\
$T_{\mathrm{w}}, T_{\mathrm{O}}$ & 0.25 & 5 & 0.25 & 5 & 0.25 & 5 \\
\hline
\end{tabular}

a From Eq. (14).

$b$ From Eq. (16).

${ }^{c}$ Based on $\left\langle k_{\mathrm{rw}}\right\rangle$ measured on two Indiana limestone cores (W, AC; Table S1) using the same oil/brine pair by Christensen and Tanino (2017a).

$d$ Based on $\left\langle k_{\mathrm{rw}}\right\rangle$ measured on three cores (O, V, AK; Table S1) (Christensen and Tanino, 2017a).

${ }^{e}$ Based on $\left\langle k_{\mathrm{rw}}\right\rangle$ measured on two cores (N, TB/I; Table S1) (Tanino and Blunt, 2013; Christensen and Tanino, 2017a).

${ }_{f} k_{\text {ro }}\left(S_{\text {oi }}\right)$ measured on the same core.

and

$$
p_{\mathrm{c}}^{+} \equiv-\frac{\mathrm{d} p_{\mathrm{c}}}{\mathrm{d} \widehat{S_{\mathrm{w}}}}\left(S_{\mathrm{wi}}\right),
$$

$p_{\mathrm{c}}^{+}>0$ and, given $0 \leq \widehat{S_{\mathrm{w}}} \leq 1, \ln \left(1-\widehat{S_{\mathrm{w}}}\right) \leq 0$.

$k_{\mathrm{rj}}\left(S_{\mathrm{w}}\right)$ was described by a generalized Corey (1954) law:

$$
\begin{aligned}
& k_{\mathrm{rw}}\left(S_{\mathrm{w}}\right)=k_{\mathrm{rw}}\left(S_{\mathrm{or}}\right){\widehat{S_{\mathrm{w}}}}^{\alpha_{\mathrm{w}}} \\
& k_{\mathrm{ro}}\left(S_{\mathrm{w}}\right)=k_{\mathrm{ro}}\left(S_{\mathrm{wi}}\right)\left(1-\widehat{S_{\mathrm{w}}}\right)^{\alpha_{\mathrm{o}}},
\end{aligned}
$$

with $\alpha_{\mathrm{j}}, k_{\mathrm{rw}}\left(S_{\mathrm{or}}\right)$, and $k_{\mathrm{ro}}\left(S_{\mathrm{wi}}\right)$ as fitting parameters. Corey (1954) proposes $\alpha_{\mathrm{w}}=$ 4 based on measurements on consolidated rock, and Brooks and Corey (1966) report $3.3 \leq \alpha_{\mathrm{w}} \leq 4.1$ in a wide range of consolidated and unconsolidated porous media. Accordingly, the exponents were constrained to $1 \leq \alpha_{\mathrm{j}} \leq 10$ here (Table 2).

If equilibrium was achieved at each $\omega$, residual saturation determined in Sec. 2.4.1, $S_{\text {or,e }}$, is the true residual saturation and $S_{\text {or }}=S_{\text {or,e. }}$. If equilibrium had not been achieved before $\omega$ was changed, $S_{\text {or,e }}$ may overestimate true $S_{\text {or }}$. Accordingly,

$$
0 \leq S_{\text {or }} \leq S_{\text {or }, \mathrm{e}} .
$$

The bounds on $k_{\mathrm{ro}}\left(S_{\mathrm{wi}}\right)$ were based on measurements of $k_{\mathrm{ro}}\left(S_{\mathrm{oi}}\right)$ in Indiana limestone by Christensen and Tanino (2017a) and in the present experiment C3. While $k_{\mathrm{ro}}\left(S_{\mathrm{oi}}\right)>1$ has been reported in water-wet sandstones and limestones previously (e.g., Berg et al, 2008; Christensen and Tanino, 2017a), we consistently measured $k_{\mathrm{ro}}\left(S_{\mathrm{oi}}\right)<1$ at $\theta_{\mathrm{a}}>90^{\circ}$ in Indiana limestone (Christensen and Tanino, 2017a; Christensen, 2018). Accordingly, the upper bound was $k_{\mathrm{ro}}\left(S_{\mathrm{wi}}\right)=1$ in all simulations. Oil permeability falls between $k_{\mathrm{ro}}\left(S_{\mathrm{oi}}\right)=0.90$ and 0.98 at $\theta_{\mathrm{a}}=135^{\circ}$ 
and comparable $S_{\text {oi }}$ (Fig. 4c). Since $k_{\text {ro }}\left(S_{\text {oi }}\right)$ decreases weakly with increasing $\theta_{\mathrm{a}}$ in mixed-wet rock (Owens and Archer, 1971; Christensen and Tanino, 2017a), we imposed $k_{\mathrm{ro}}\left(S_{\mathrm{wi}}\right)=0.90$ as a conservative lower limit for all $\theta_{\mathrm{a}} \leq 135^{\circ}$ simulations. $k_{\text {ro }}\left(S_{\text {oi }}\right)(=0.76)$ was measured on core C3 immediately before the core was centrifuged and, accordingly, we took $k_{\mathrm{ro}}\left(S_{\mathrm{wi}}\right)=k_{\mathrm{ro}}\left(S_{\mathrm{oi}}\right)$ as the lower limit for C3.

After breakthrough, oil saturation in a mixed-wet rock undergoing waterflooding is elevated at the downstream end of the core where $p_{\mathrm{c}}=0$ due to capillary end effects, which in turn gives rise to an elevated cross-sectionally-averaged pressure gradient. Thus the effective water relative permeability,

$$
\left\langle k_{\mathrm{rw}}\right\rangle=\frac{\mu_{\mathrm{w}}}{k} \frac{U_{\mathrm{w}}}{\Delta p_{\mathrm{w}} / L},
$$

calculated directly from the pressure drop measured across the length of the core, $\Delta p_{\mathrm{w}}(t)$, at the end of a waterflood, where $U_{\mathrm{w}}=Q_{\mathrm{w}} / A, Q_{\mathrm{w}}$ is the volumetric flow rate of brine, and $A$ is the bulk cross-sectional area, must be smaller than $k_{\mathrm{rw}}\left(S_{\mathrm{or}}\right)$ if a large fraction of the grain surface has been rendered hydrophobic. To ensure this criterion is met, we restrict our consideration to maximum $S_{\text {oi }}$ (Table 1 ). End-point water relative permeability was then constrained to

$$
1 \leq \frac{k_{\mathrm{rw}}\left(S_{\mathrm{or}}\right)}{\left\langle k_{\mathrm{rw}}\right\rangle} \leq 2
$$

where $\left\langle k_{\mathrm{rw}}\right\rangle$ is the end-point effective water relative permeability measured by Tanino and Blunt (2013); Christensen and Tanino (2017a) at the end of waterflood experiments using the same oil/brine pair but in different cores; further details can be found in Table 2. To account for variations between cores, the smallest and largest $\left\langle k_{\mathrm{rw}}\right\rangle$ measured for that oil/brine pair were used to define the lower and upper bounds, respectively.

\subsection{Waterflood}

After $S_{\text {oi }}$ was established, the porous plate was removed and brine was injected into the core at constant Darcy velocity of either $U_{\mathrm{w}}=1.5$ or $3.0 \mu \mathrm{m} / \mathrm{s}$ for a minimum of $90 \mathrm{pv}$. The injection velocities correspond to microscopic capillary numbers,

$$
\mathrm{Ca}=\frac{\mu_{\mathrm{w}} U_{\mathrm{w}} / \phi}{\sigma\left|\cos \theta_{\mathrm{a}}\right|}
$$

between $6.7 \times 10^{-7}$ and $1.3 \times 10^{-6}$ (Table 1 ).

Pressure was measured at the two ends of the core at 2 min.-intervals in 6 waterfloods (N, O, V, W, AD, AH) and at selected instances in the others (D, TB/I); $\left\langle S_{\mathrm{o}}\right\rangle(t)$ was measured at three to five instances by mass balance. To ensure meaningful history matching, we only consider waterfloods where the core-averaged oil saturation, $\left\langle S_{\circ}\right\rangle(t)$, was measured at least three times during the waterflood in the present paper. 
Table 3 Upper and lower bounds for each optimized parameter: waterfloods.

\begin{tabular}{|c|c|c|c|c|c|c|c|c|c|c|c|c|c|c|c|c|}
\hline \multirow[b]{2}{*}{ parameter } & \multicolumn{2}{|c|}{ W } & \multicolumn{2}{|c|}{ D } & \multicolumn{2}{|c|}{$\mathrm{O}$} & \multicolumn{2}{|c|}{$\mathrm{V}$} & \multicolumn{2}{|c|}{$\mathrm{AD}$} & \multicolumn{2}{|c|}{$\mathrm{AH}$} & \multicolumn{2}{|c|}{$\mathrm{N}$} & \multicolumn{2}{|c|}{ gुB/I } \\
\hline & $\min$ & $\max$ & $\min$ & $\max$ & $\min$ & $\max$ & $\min$ & $\max$ & $\min$ & $\max$ & $\min$ & $\max$ & $\min$ & $\max$ & $\mathrm{m}$ & $\max$ \\
\hline$p_{\mathrm{c}}^{*}[\mathrm{kPa}]$ & 6.296 & 157.4 & 4.707 & 117.7 & 23.68 & 592.0 & 16.50 & 412.4 & 26.93 & 898.0 & 19.16 & 638.9 & 11.19 & 279.9 & $26.58^{\circ}$ & 664.4 \\
\hline$S_{\mathrm{w}}(0)$ & $0.229^{a}$ & $0.532^{c}$ & $0.229^{a}$ & $0.523^{c}$ & $0.229^{a}$ & $0.547^{c}$ & $0.229^{a}$ & $0.541^{c}$ & $0.234^{d}$ & $0.538^{c}$ & $0.239^{d}$ & $0.540^{c}$ & $0.187^{d}$ & $0.385^{d}$ & $0.2 \phi 8 \delta^{\circ}$ & $0.229^{e}$ \\
\hline$\beta$ & 0.001 & 100 & 0.001 & 100 & 0.001 & 10 & 0.001 & 10 & 0.001 & 5 & 0.001 & 5 & 0.001 & 5 & $0.00 \mathrm{E}$ & 5 \\
\hline $1-S_{\mathrm{or}}$ & 0.683 & 1 & 0.686 & 1 & 0.730 & 1 & 0.754 & 1 & 0.701 & 1 & 0.751 & 1 & 0.632 & 1 & 0.65 & 1 \\
\hline$k_{\mathrm{rw}}\left(S_{\mathrm{or}}\right)$ & 0.369 & 0.739 & 0.246 & 0.492 & 0.499 & 0.999 & 0.502 & 1.004 & 0.396 & 1 & 0.655 & 1.311 & 0.629 & 1.258 & 0.833 & 1.667 \\
\hline$k_{\mathrm{ro}}\left(S_{\mathrm{wi}}\right)$ & $0.792^{b}$ & 1 & 0.792 & 1 & 0.792 & 1 & 0.792 & 1 & 0.792 & 1 & $0.898^{b}$ & 1 & $0.661^{b}$ & 1 & $0.66 \mathrm{E}$ & 1 \\
\hline$L_{\mathrm{w}}$ & 1 & 10 & 1 & 10 & 1 & 10 & 1 & 10 & 1 & 10 & 1 & 10 & 1.027 & 6.283 & I & 10 \\
\hline$L_{\mathrm{o}}$ & 1 & 10 & 1 & 10 & 1 & 10 & 1 & 10 & 1 & 10 & 1 & 10 & 1 & 10 & $E$ & 10 \\
\hline$E_{\mathrm{w}}$ & 1 & 50 & 1 & 50 & 1 & 50 & 1 & 50 & 1 & 50 & 1 & 50 & 1 & 50 & 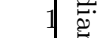 & 50 \\
\hline$E_{\mathrm{o}}$ & 1 & 100 & 1 & 100 & 1 & 100 & 1 & 100 & 1 & 100 & 1 & 100 & 1 & 100 & ن & 100 \\
\hline$T_{\mathrm{w}}$ & 0.25 & 5 & 0.25 & 5 & 0.25 & 5 & 0.25 & 5 & 0.25 & 5 & 0.25 & 5 & 0.887 & 1.158 & $0 . \$ 5 \Xi$ & 5 \\
\hline$T_{\mathrm{o}}$ & 0.25 & 5 & 0.25 & 5 & 0.25 & 5 & 0.25 & 5 & 0.25 & 5 & 0.25 & 5 & 0.25 & 5 & $0 . \$ 50^{z}$ & 5 \\
\hline $\begin{array}{l}a^{a} \text { From Eq. } \\
{ }^{b} k_{\mathrm{ro}}\left(S_{\mathrm{oi}}\right) \mathrm{m} \\
{ }^{c} \text { From Eq. } \\
{ }^{d} \text { From Eq. } \\
{ }^{e} \text { From Efter agein } \\
\text { was constrai } \\
\text { by mass bala }\end{array}$ & $\begin{array}{l}\text { b). } \\
\text { isured o } \\
\text { a). } \\
\text { c). } \\
\text { at } S_{\text {oi }} \text {, } \\
\text { d to } 1 \\
\text { ce. }\end{array}$ & $\begin{array}{l}\text { same co } \\
\text { is core y } \\
S_{\mathrm{w}}(0) / /\end{array}$ & $\begin{array}{l}\text { subme } \\
(0) \leq\end{array}$ & , whe & $\left.S_{\mathrm{w}}\right\rangle(0$ & $\begin{array}{l}\text { ays i } \\
0.208\end{array}$ & $\begin{array}{l}\text { Amot } \\
\text { the }\end{array}$ & $\begin{array}{l}11 \text { pri } \\
\text {-aver }\end{array}$ & $\begin{array}{l}\text { wate } \\
\text { satur }\end{array}$ & $\begin{array}{l}\text { ding } \\
\text { n at }\end{array}$ & $\begin{array}{l}\text { nino a } \\
\text { end of }\end{array}$ & $\begin{array}{l}\text { Blunt } \\
\text { ontane }\end{array}$ & $\begin{array}{l}\text { 13). Th } \\
\text { imbibi }\end{array}$ & $\begin{array}{l}\text { ptimiz } \\
\text { n mea }\end{array}$ & $\begin{array}{l}\text { on } \\
\text { ed }\end{array}$ & \\
\hline
\end{tabular}



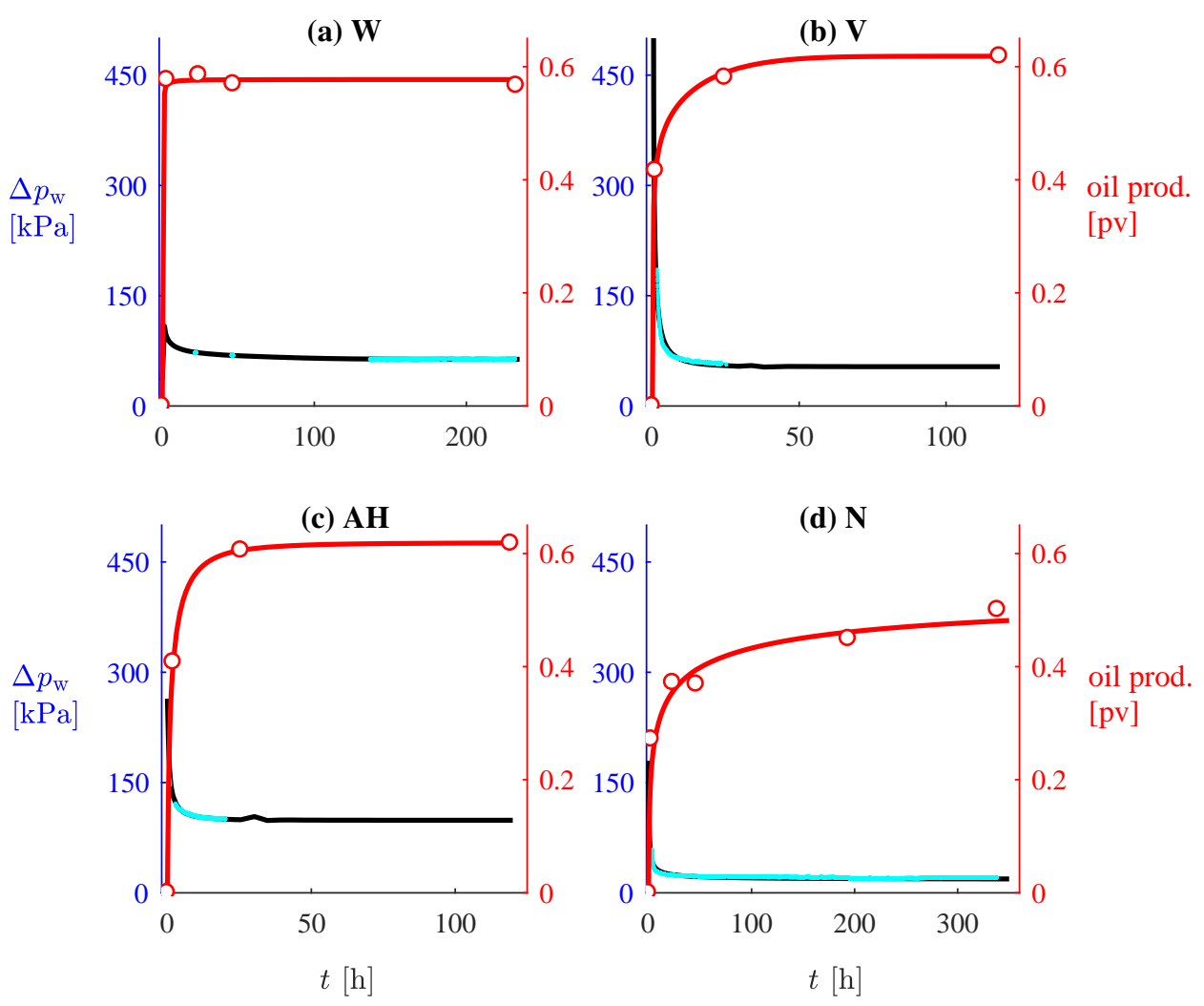

Fig. 3 Measured $\Delta p_{\mathrm{w}}(t)$ (cyan dots, left axis) and cumulative oil production (red $\circ$, right axis) during waterfloods $\mathrm{W}(\mathrm{a}), \mathrm{V}(\mathrm{b}), \mathrm{AH}(\mathrm{c})$, and $\mathrm{N}(\mathrm{d})$, and the corresponding values predicted by numerical simulation (solid line).

\subsection{1 $k_{i}\left(S_{w}\right)$ and $p_{c}\left(S_{w}\right)$ determination}

The conventional approach in coreflood history matching is to use independently measured $p_{\mathrm{c}}\left(S_{\mathrm{w}}\right)$ (typically one measured by centrifuge assuming equilibrium) as a fixed parameter (Christensen and Tanino, 2018). However, this approach assumes that (a) Leverett-J scaling correctly captures variations in $k$ and $\phi$ between cores and $\sigma$ and contact angle between different fluid pairs, (b) dynamic effects are negligible, and (c) equilibrium was achieved at each rotation speed during the multi-speed centrifuge experiment from which $p_{\mathrm{c}}\left(S_{\mathrm{w}}\right)$ is obtained. Yaralidarani and Shahverdi (2018) report significant and systematic disagreement between $p_{\mathrm{c}}\left(S_{\mathrm{w}}\right)$ derived from centrifuge and coreflood experiments in the same rock; we see similar systematic deviation in the present analysis (Fig. 8).

In the present study, we simultaneously optimized both $k_{\mathrm{rj}}\left(S_{\mathrm{w}}\right)$ and $p_{\mathrm{c}}\left(S_{\mathrm{w}}\right)$ by history matching simulated pressure drop across the length of the core, $\Delta p_{\mathrm{w}}(t)$, and oil production to measured values in the least-squares sense. The numerical 
simulator used and the numerical scheme are the same as those used in history matching to the centrifuge experiments (Sec. 2.4.2).

Relative permeabilities were modelled using the so-called LET correlations (Lomeland et al, 2005):

$$
\begin{aligned}
& k_{\mathrm{ro}}\left(S_{\mathrm{w}}\right)=k_{\mathrm{ro}}\left(S_{\mathrm{wi}}\right) \frac{\left(1-\widehat{S_{\mathrm{w}}}\right)^{L_{\mathrm{o}}}}{\left(1-\widehat{S_{\mathrm{w}}}\right)^{L_{\mathrm{o}}}+E_{\mathrm{o}}{\widehat{S_{\mathrm{w}}}}^{T_{\mathrm{o}}}} \\
& k_{\mathrm{rw}}\left(S_{\mathrm{w}}\right)=k_{\mathrm{rw}}\left(S_{\mathrm{or}}\right) \frac{\widehat{S_{\mathrm{w}}} L_{\mathrm{w}}}{{\widehat{S_{\mathrm{w}}}}^{L_{\mathrm{w}}}+E_{\mathrm{w}}\left(1-\widehat{S_{\mathrm{w}}}\right)^{T_{\mathrm{w}}}}
\end{aligned}
$$

where $k_{\mathrm{rw}}\left(S_{\mathrm{or}}\right), k_{\mathrm{ro}}\left(S_{\mathrm{wi}}\right)$, and $\left(L_{\mathrm{j}}, E_{\mathrm{j}}, T_{\mathrm{j}}\right)$ are fitting parameters; $L_{\mathrm{j}}, E_{\mathrm{j}}, T_{\mathrm{j}}>0$. Multiple combinations of $\left(L_{\mathrm{j}}, E_{\mathrm{j}}, T_{\mathrm{j}}\right)$ can be used to describe similar $k_{\mathrm{j}}\left(S_{\mathrm{w}}\right)$ profiles and hence achieve comparable agreement to data. Recently, Yaralidarani and Shahverdi (2018) derived optimized values of $O(1)$ for these parameters from waterflood experiments in low $k$, carbonate reservoir rock samples. Similarly, Lomeland et al (2005) report that $L_{\mathrm{j}} \geq 1$ and $T_{\mathrm{j}} \geq 0.5$ typically. To facilitate comparison with the literature, we constrained the optimization to $1 \leq L_{\mathrm{j}} \leq 10 ; 1 \leq E_{\mathrm{w}} \leq 50$; $1 \leq E_{\mathrm{o}} \leq 100 ; 0.25 \leq T_{\mathrm{j}} \leq 5 .{ }^{6}$ Sensitivity analyses were undertaken to ensure that optimized values of $\left(L_{\mathrm{j}}, E_{\mathrm{j}}, T_{\mathrm{j}}\right)$ for each phase do not all coincide with an upper or lower limit. As in the centrifuge analysis, $S_{\mathrm{wi}}=0$.

A generalized form of Eq. (9) (CYDAREX, 2017):

$$
p_{\mathrm{c}}\left(S_{\mathrm{w}}\right)=\gamma p_{\mathrm{c}}^{*}\left[\ln \frac{1-{\widehat{S_{\mathrm{w}}}}^{\beta}}{{\widehat{S_{\mathrm{w}}}}^{\beta}}-\ln \frac{1-\widehat{S_{\mathrm{w}}}\left(p_{\mathrm{c}}=0\right)^{\beta}}{\widehat{S_{\mathrm{w}}}(0)^{\beta}}\right] \text {, }
$$

where dimensionless fitting parameter $\beta(>0)$ characterizes skewness, and

$$
\gamma=\frac{1}{2 \beta}\left(1-0.5^{\beta}\right)
$$

such that

$$
p_{\mathrm{c}}^{*} \equiv-\frac{\mathrm{d} p_{\mathrm{c}}}{\mathrm{d} \widehat{S_{\mathrm{w}}}}\left(\widehat{S_{\mathrm{w}}}=0.5\right),
$$

was used to describe capillary pressure to achieve better agreement with experiment. ${ }^{7}$ Note that $p_{\mathrm{c}}^{*}>0$.

Combined, twelve fitting parameters $-p_{\mathrm{c}}^{*}, \widehat{S_{\mathrm{w}}}(0), \beta,\left(L_{\mathrm{j}}, E_{\mathrm{j}}, T_{\mathrm{j}}\right), k_{\mathrm{ro}}\left(S_{\mathrm{wi}}\right)$, $k_{\mathrm{rw}}\left(S_{\mathrm{or}}\right)$, and $S_{\text {or }}$ - were iteratively adjusted within the bounds described below until the combination that minimized the least-squares error was identified (e.g., Fig. 3). The upper and lower limits for each fitting parameter imposed on the optimization are described below.

6 One exception is $L_{\mathrm{w}}$ and $T_{\mathrm{w}}$ for waterflood $\mathrm{N}$, which were constrained to a narrower range

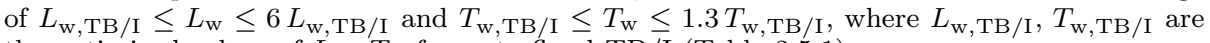
the optimized values of $L_{\mathrm{w}}, T_{\mathrm{w}}$ for waterflood TB/I (Table 2.5.1).

7 History matching using Eq. (9) instead of Eq. (19) yields unphysically large $k_{\mathrm{rw}}\left(S_{\mathrm{or}}\right)$ for waterflood $\mathrm{N}$ and $S_{\mathrm{w}}(0)$ for all waterfloods, suggesting that Eq. (9) does not accurately capture the $S_{\mathrm{w}}$ dependence of $p_{\mathrm{c}}$. 
Premature termination of the waterflood and capillary end effects both elevate core-averaged oil saturation at the end of a waterflood above the true $S_{\text {or }}$. Accordingly, the upper bound on $S_{\text {or }}$ is given by $\left\langle S_{\mathrm{o}}\right\rangle$ measured at the end of each waterflood experiment. $S_{\mathrm{w}}(0)$ was constrained based on direct measurements as given by Eqs. $(7 \mathrm{a}-7 \mathrm{c}) \cdot p_{\mathrm{c}}^{*}$ was constrained to:

$$
\frac{1}{5} \leq \frac{J^{*}}{J_{\mathrm{C}}^{+}} \leq 5
$$

where

$$
\left.\begin{array}{l}
J^{*} \\
J^{+}
\end{array}\right\}=\left\{\begin{array}{l}
p_{\mathrm{c}}^{*} \\
p_{\mathrm{c}}^{+}
\end{array}\right\} \frac{\sqrt{k / \phi}}{\sigma\left|\cos \theta_{\mathrm{a}}\right|}
$$

and subscript ' $\mathrm{C}$ ' denotes optimized values derived from the centrifuge experiment for the same $\left(\sigma, \theta_{\mathrm{a}}\right)^{8}$ using Eq. (13) (cf. Sec. 2.4.2). $\beta$ was constrained to

$$
\beta \leq \begin{cases}100 & \text { if } \theta_{\mathrm{a}}=110^{\circ} \\ 10 & \text { if } \theta_{\mathrm{a}}=125^{\circ} \\ 5 & \text { if } \theta_{\mathrm{a}}=135^{\circ}, 150^{\circ}\end{cases}
$$

The constraints on $k_{\mathrm{rw}}\left(S_{\mathrm{or}}\right)$ were chosen in the same way as for the centrifuge experiments. Similarly, oil permeability was constrained as before to

$$
k_{\text {ro }}\left(S_{\text {oi }}\right) \leq k_{\text {ro }}\left(S_{\text {wi }}\right) \leq 1 .
$$

For cores $\mathrm{W}, \mathrm{AH}$, and $\mathrm{N}, k_{\mathrm{ro}}\left(S_{\mathrm{oi}}\right)$ measured at the end of primary drainage by Christensen and Tanino (2017a) was used. ${ }^{9}$ For cores D and TB/I, $k_{\text {ro }}\left(S_{\text {oi }}\right)$ measured on cores W and N, respectively, were used to evaluate Eq. (24); for all other waterfloods $(\mathrm{O}, \mathrm{V}, \mathrm{AD})$, the lower bound was taken to be the smallest $k_{\mathrm{ro}}\left(S_{\mathrm{oi}}\right)$ measured at $\theta_{\mathrm{a}}<150^{\circ}$.

\subsection{Uncertainty analysis}

Several studies have indicated that the inversion of oil production data to $k_{\mathrm{r}}\left(S_{\mathrm{w}}\right)$ and $p_{\mathrm{c}}\left(S_{\mathrm{w}}\right)$ from a single, transient (unsteady state), single-step displacement experiment is non-unique, i.e., can yield multiple sets of optimized parameters that fit comparably well to the experimental data (see, e.g., Chen et al 1999 and references therein). In this paper, we consider the sensitivity of the optimized parameters to two factors (Subbey et al, 2006):

- choice of parametric model for $k_{\mathrm{rj}}\left(S_{\mathrm{w}}\right)$ in inverting centrifuge data, and

- choice of parameter range for $k_{\mathrm{rw}}\left(S_{\mathrm{w}}\right)$ for experiments for which the derived $k_{\mathrm{rw}}\left(S_{\text {or }}\right)$ exceeds one.

8 For waterfloods $\mathrm{AD}, \mathrm{AH}\left(\theta_{\mathrm{a}}=135^{\circ}\right)$, optimized values of $J_{\mathrm{C}}^{+}$at $\theta_{\mathrm{a}}=125^{\circ}$ and $150^{\circ}$ were considered. The larger of the two were used to define the upper limit and the smaller of the two were used to define the lower limit of $\widetilde{J}^{*}$ [Eq. (22)].

9 We did not simply take $k_{\mathrm{ro}}\left(S_{\mathrm{wi}}\right)=k_{\mathrm{ro}}\left(S_{\mathrm{oi}}\right)$ as a fixed parameter because the curvature of the derived $k_{\mathrm{ro}}\left(S_{\mathrm{w}}\right)$ is such that $k_{\mathrm{ro}}\left(S_{\mathrm{w}}\right)$ displays a relatively strong dependence on $S_{\mathrm{w}}$ near irreducible water saturation (Fig. 4). 
Table 4 Summary of optimized parameters derived using either a generalized Corey (1954) law [Eq. (13)] or LET correlations [Eq. (18)] to describe $k_{\mathrm{rj}}\left(S_{\mathrm{w}}\right) . S_{\mathrm{w}}\left(p_{\mathrm{c}}=0\right)$ is given by Eq. (11). The two values of effective $\theta_{\mathrm{a}}$ for each history match were calculated by matching $J^{+}$and $J(0)$, respectively, with those of experiment C3 [Eq. (28)]; values are given to the closest $5^{\circ}$.

\begin{tabular}{|c|c|c|c|c|c|c|c|}
\hline & & \multicolumn{2}{|c|}{$\mathrm{C} 2$} & \multicolumn{2}{|c|}{$\mathrm{C} 1$} & \multicolumn{2}{|c|}{ C3 } \\
\hline & & Eq. (13) & LET & Eq. (13) & LET & Eq. (13) & LET \\
\hline \multirow{17}{*}{$\begin{array}{l}\text { optimized } \\
\text { parameters }\end{array}$} & $p_{\mathrm{c}}^{+}[\mathrm{kPa}]$ & 30.02 & 23.35 & 90.811 & 64.84 & 97.326 & 78.800 \\
\hline & $\begin{array}{l}p_{\mathrm{c}}\left(S_{\mathrm{wi}}\right) \\
{[\mathrm{kPa}]}\end{array}$ & 8.598 & 7.329 & 27.67 & 21.24 & 33.05 & 26.86 \\
\hline & $S_{\text {or }}$ & 0.185 & 0.244 & 0.069 & 0.182 & 0.042 & 0.108 \\
\hline & $k_{\mathrm{rw}}\left(S_{\mathrm{or}}\right)$ & 0.370 & 0.796 & 0.499 & 1.017 & 1.661 & 1.661 \\
\hline & $k_{\mathrm{ro}}\left(S_{\mathrm{wi}}\right)$ & 0.905 & 0.899 & 0.899 & 0.899 & 1.000 & 1.000 \\
\hline & $L_{\mathrm{w}}$ & - & 5.952 & - & 1.008 & - & 1.476 \\
\hline & $E_{\mathrm{W}}$ & - & 1.803 & - & 1.008 & - & 11.057 \\
\hline & $T_{\mathrm{w}}$ & - & 4.917 & - & 4.935 & - & 4.021 \\
\hline & $L_{\mathrm{O}}$ & - & 2.119 & - & 1.720 & - & 3.247 \\
\hline & $E_{\mathrm{o}}$ & - & 99.823 & - & 99.892 & - & 99.965 \\
\hline & $T_{\mathrm{o}}$ & - & 0.497 & - & 1.184 & - & 4.227 \\
\hline & $\alpha_{\mathrm{w}}$ & 5.487 & - & 4.821 & - & 1 & - \\
\hline & $\alpha_{\mathrm{o}}$ & 5.474 & - & 6.617 & - & 6.484 & - \\
\hline & $\begin{array}{l}k_{\mathrm{w}}\left(S_{\mathrm{or}}\right) \\
/ k_{\mathrm{o}}\left(S_{\mathrm{wi}}\right)\end{array}$ & 0.41 & 0.89 & 0.56 & 1.1 & 1.7 & 1.7 \\
\hline & $\begin{array}{l}k_{\mathrm{rw}}\left(S_{\mathrm{or}}\right) / \\
\left(1-S_{\mathrm{or}}\right)^{2}\end{array}$ & 0.56 & 1.4 & 0.58 & 1.5 & 1.8 & 2.1 \\
\hline & $S_{\mathrm{w}}(0)$ & 0.20 & 0.20 & 0.25 & 0.23 & 0.28 & 0.26 \\
\hline & $\begin{array}{l}\text { effective } \\
\theta_{\mathrm{a}}\left[^{\circ}\right]\end{array}$ & 100,100 & 100,100 & 130,125 & 125,125 & - & - \\
\hline \multicolumn{2}{|c|}{$\begin{array}{l}\text { lines in Figs. 4, 6, 7, 8, } 11 \\
\text { markers in Figs. } 5,9,10 \mathrm{a}, \mathrm{S} 4\end{array}$} & $\underset{\Delta}{\text { solid }}$ & $\begin{array}{c}\text { dashed } \\
\triangle\end{array}$ & solid & $\begin{array}{c}\text { dashed } \\
\triangle\end{array}$ & $\underset{\Delta}{\text { solid }}$ & $\begin{array}{c}\text { dashed } \\
\triangle\end{array}$ \\
\hline
\end{tabular}

To evaluate the sensitivity to the first factor, the inversion of the centrifuge data was repeated with LET correlations. The constraints on $L_{\mathrm{j}}, E_{\mathrm{j}}, T_{\mathrm{j}}$, were chosen in the same way as for the waterflood experiments (Sec. 2.5.1). For experiment C3 only, the lower bound on $E_{\mathrm{w}}$ was relaxed to 0.01 (Table 2).

To evaluate the sensitivity to the second factor, we repeated the inversion of data from both centrifuge experiments and waterfloods by restricting the range of $k_{\mathrm{rw}}\left(S_{\mathrm{or}}\right)$ to $k_{\mathrm{rw}}\left(S_{\mathrm{or}}\right) \leq 1$. We only performed this analysis for experiments for which the optimized $k_{\mathrm{rw}}\left(S_{\mathrm{or}}\right)$, derived as described in Secs. 2.4.2 and 2.5.1, exceeds one. The parameter range of all other fitting parameters remain unchanged (cf. Tables 2, 2.5.1).

\section{Results}

Fig. 2 presents simulated (lines) and measured (markers) cumulative oil production during the multi-speed centrifuge experiments. Excellent agreement is achieved for all $\theta_{\text {a }}$ considered, indicating successful optimization. Similarly, good agreement was achieved for waterfloods overall (e.g., Figs. 3, S5, S6).

Optimized values for parameters are summarized in Tables 4 and 5 and those with physical meaning, specifically $p_{\mathrm{c}}^{+}, p_{\mathrm{c}}^{*}, S_{\mathrm{w}}(0), \beta, k_{\mathrm{ro}}\left(S_{\mathrm{wi}}\right), k_{\mathrm{rw}}\left(S_{\mathrm{or}}\right)$, and $S_{\mathrm{or}}$ 
Table 5 Summary of optimized parameters derived from waterfloods.

\begin{tabular}{|c|c|c|c|c|c|c|c|c|c|}
\hline & & W & D & $\mathrm{O}$ & $\mathrm{V}$ & $\mathrm{AD}$ & $\mathrm{AH}$ & $\mathrm{N}$ & $\mathrm{TB} / \mathrm{I}$ \\
\hline \multirow{14}{*}{$\begin{array}{l}\text { optimized } \\
\text { parameters }\end{array}$} & \multirow{2}{*}{$\begin{array}{l}p_{\mathrm{c}}^{*}[\mathrm{kPa}] \\
\beta\end{array}$} & 33.07 & 28.69 & 23.68 & 37.62 & 72.12 & 20.51 & 15.18 & 76.99 \\
\hline & & 95.575 & 98.847 & 4.144 & 4.665 & 0.497 & 1.510 & 5.000 & 0.013 \\
\hline & $S_{\mathrm{w}}(0)$ & 0.513 & 0.523 & 0.540 & 0.541 & 0.310 & 0.500 & 0.187 & 0.210 \\
\hline & $S_{\text {or }}$ & 0.304 & 0.276 & 0.270 & 0.226 & 0.261 & 0.235 & 0.161 & 0.164 \\
\hline & $k_{\mathrm{rw}}\left(S_{\mathrm{or}}\right)$ & 0.383 & 0.284 & 0.580 & 0.665 & 0.765 & 0.707 & 1.249 & 1.191 \\
\hline & $k_{\mathrm{ro}}\left(S_{\mathrm{wi}}\right)$ & 0.998 & 0.794 & 0.951 & 0.999 & 0.906 & 0.920 & 0.665 & 0.697 \\
\hline & $L_{\mathrm{w}}$ & 1.029 & 3.023 & 3.443 & 2.776 & 6.283 & 1.137 & 2.509 & 1.027 \\
\hline & $E_{\mathrm{w}}$ & 4.082 & 12.119 & 17.139 & 26.829 & 1.027 & 1.000 & 1.002 & 1.009 \\
\hline & $T_{\mathrm{w}}$ & 0.480 & 2.132 & 1.507 & 2.755 & 0.754 & 1.158 & 1.157 & 0.887 \\
\hline & $L_{\mathrm{O}}$ & 1.783 & 2.297 & 1.000 & 1.000 & 1.000 & 1.497 & 3.010 & 2.823 \\
\hline & $E_{\mathrm{o}}$ & 1.029 & 99.952 & 74.579 & 73.035 & 33.941 & 13.517 & 13.735 & 4.160 \\
\hline & $T_{\mathrm{o}}$ & 0.257 & 0.250 & 0.302 & 0.394 & 0.526 & 0.614 & 0.250 & 1.571 \\
\hline & $\begin{array}{l}k_{\mathrm{w}}\left(S_{\mathrm{or}}\right) \\
/ k_{\mathrm{o}}\left(S_{\mathrm{wi}}\right)\end{array}$ & 0.38 & 0.36 & 0.61 & 0.67 & 0.84 & 0.77 & 1.88 & 1.71 \\
\hline & $\begin{array}{l}k_{\mathrm{rw}}\left(S_{\mathrm{or}}\right) / \\
\left(1-S_{\mathrm{or}}\right)^{2}\end{array}$ & 0.8 & 0.5 & 1.1 & 1.1 & 1.4 & 1.2 & 1.8 & 1.7 \\
\hline
\end{tabular}

are presented in Figs. 9, 5a, and 10 as functions of $\theta_{\mathrm{a}}$. Below, we discuss each separately.

\subsection{Relative permeability}

Fig. 4 presents best-fit LET correlations [Eq. (18)] for both waterfloods and centrifuge experiments and best-fit Corey (1954)-type functions [Eq. (13)] for centrifuge experiments only. Superposed are $k_{\text {ro }}\left(S_{\text {oi }}\right)$ measured at the end of primary drainage in selected experiments (red squares); further details of the procedure are reported by Christensen and Tanino (2017a) and are thus omitted here.

In the discussion that follows, we focus on the best-fit Corey (1954)-type functions for the centrifuge experiments.

\subsubsection{End-point relative permeabilities}

End-point relative permeabilities to oil and water broadly decrease and increase, respectively, with increasing $\theta_{\mathrm{a}}$ (Tables 4,5 ). The contact angle dependence is consistent with previous studies that present direct measurements of end-point relative permeability (Owens and Archer, 1971; Christensen and Tanino, 2017a). The ratio of the end-point permeabilities, $k_{\mathrm{rw}}\left(S_{\mathrm{or}}\right) / k_{\mathrm{ro}}\left(S_{\mathrm{wi}}\right)$, is well described by a second order polynomial fitted to the data (Fig. 5a, dashed)

$$
\frac{k_{\mathrm{rw}}\left(S_{\mathrm{or}}\right)}{k_{\mathrm{ro}}\left(S_{\mathrm{wi}}\right)}=9.2 \times 10^{-4} \theta_{\mathrm{a}}^{2}-0.21 \theta_{\mathrm{a}}+12,
$$

where $\theta_{\mathrm{a}}$ is given in units of ${ }^{\circ}$ (not radians) for both the centrifuge experiments and waterfloods.

A positive correlation of $k_{\mathrm{rw}}$ with $\theta_{\mathrm{a}}$ can be qualitatively explained as follows. A non-wetting phase occupies the center of larger pores and thus experiences less friction against the grain surface than a wetting phase at the same saturation. In-situ contact angles are expected to be heterogeneous at the core-scale owing 


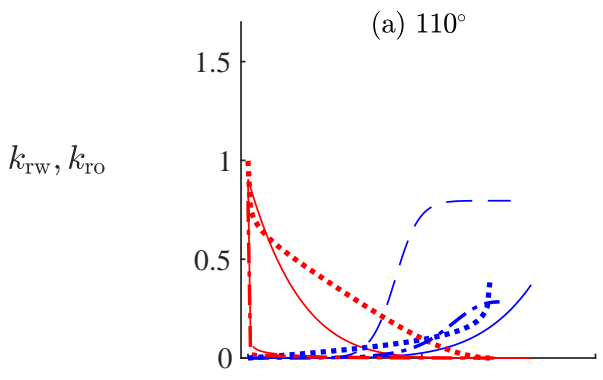

(c) $135^{\circ}$

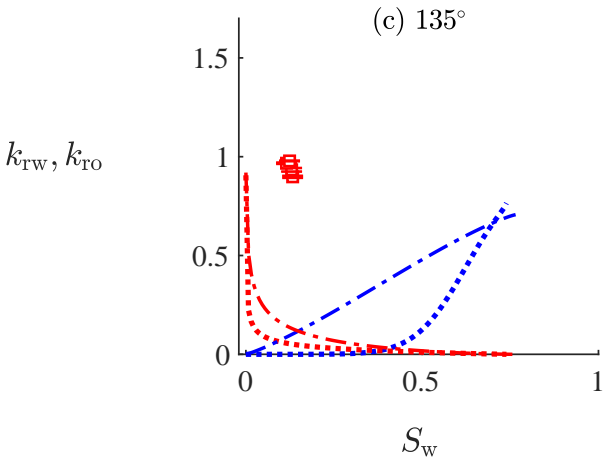

(b) $125^{\circ}$

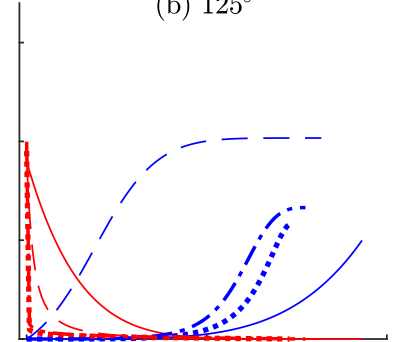

(d) $150^{\circ}$

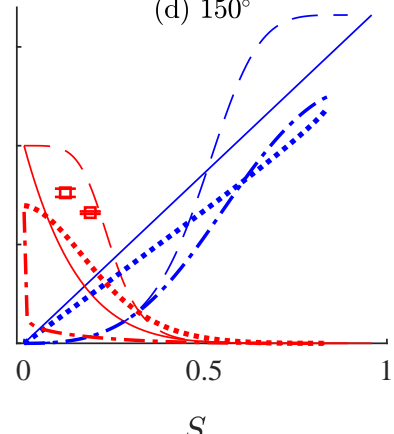

Fig. 4 Best-fit oil (red) and brine (blue) relative permeability functions at $\theta_{\mathrm{a}}=110^{\circ}$ (a), $125^{\circ}$ (b), $135^{\circ}$ (c) and $150^{\circ}$ (d) derived from centrifuge experiments (solid lines, dashed) and waterfloods (dotted, dash-dotted). Solid lines are best-fit Eq. (13) functions; all other lines are LET correlations [Eq. (18)]. For each $\theta_{\mathrm{a}}$, the dash-dotted line depicts the waterflood on the core with the larger $k / \phi(\mathrm{D}, \mathrm{V}, \mathrm{AH}, \mathrm{N})$. See Tables 4,5 for the optimized values of the relevant parameters. Superposed are direct measurements of $k_{\mathrm{ro}}\left(S_{\mathrm{oi}}\right)$ at the end of primary drainage in experiments AH, AF, U, Z, N, and C3 (Christensen and Tanino, 2017a) (red $\square$ ); vertical bars depict the uncertainty, but they are smaller than the marker size and can hardly be discerned. Recall that centrifuge experiments were not performed at $\theta_{\mathrm{a}}=135^{\circ}$.
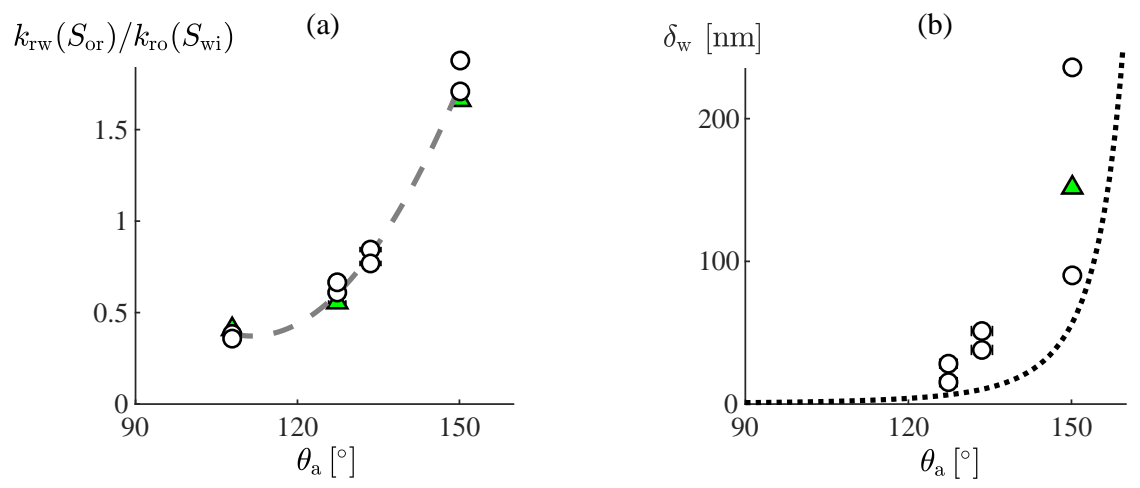

Fig. 5 Ratio of end-point relative permeabilities (a) and equivalent slip length (b) derived from centrifuge experiments (green $\mathbf{\Delta}$ ) and waterfloods (o). Horizontal bars depict standard error of the mean in the measured $\theta_{\mathrm{a}}$ (Christensen and Tanino, 2017b); where they are not visible they are smaller than the marker size. Dashed line in (a), Eq. (25), is intended as a guide to the eye only. Dotted line in (b) is the scaling $\delta_{\mathrm{w}}=\left(1+\cos \theta_{\mathrm{a}}\right)^{-2}$ proposed by Huang et al (2008). Note that only positive $\delta_{\mathrm{w}}$ are shown here. 
to variations in pore geometry and sub-pore scale heterogeneities in mineralogy, grain roughness, and oil distribution; for example, Scanziani et al (2017) found in-situ contact angles in a mixed-wet Ketton limestone sample to vary between $0^{\circ}$ and $135^{\circ}$. As $\theta_{\mathrm{a}}$ increases, a larger fraction of pores will become oil-wetting and, accordingly, a larger fraction of pores will conduct water more easily, resulting in higher $k_{\mathrm{rw}}$ at late $t$ /large $S_{\mathrm{w}}$. Further insight requires visualization of the porescale distribution of the fluids at different $\theta_{\mathrm{a}}$ using, e.g., X-ray micro-computed tomography (e.g., Singh et al, 2016; Alhammadi et al, 2017) or microfluidics (e.g., Bowden et al, 2016).

The negative correlation between $k_{\mathrm{ro}}\left(S_{\mathrm{wi}}\right)$ and $\theta_{\mathrm{a}}$ is more difficult to explain. Owens and Archer (1971) attributed such correlations to oil reconfiguration due to wettability alteration at $S_{\text {oi }}$. While plausible, signatures of such reconfiguration cannot be identified in drainage capillary pressure measurements (Fig. S2). Another explanation is that the length of the alkyl chain on the naphthenic acid constituent in the oil phase that has adsorbed onto the grain surface increases as $\theta_{\mathrm{a}}$ increases which may in turn reduce the local cross-sectional area available to flow (cf. Christensen and Tanino, 2017a). Further insight requires a detailed investigation of the surface chemistry at the molecular level.

Optimized $k_{\text {rw }}\left(S_{\text {or }}\right)$ exceeds one at the largest $\theta_{\mathrm{a}}\left(=150^{\circ}\right)$ for both waterfloods and centrifuge experiments and, for the latter, irrespective of the model used to describe $k_{\mathrm{r}}\left(S_{\mathrm{w}}\right)$ (Tables 4,5$)$. Pore network simulators (e.g., Valvatne and Blunt, 2004; Joekar-Niasar et al, 2008; Ryazanov et al, 2010), commercial reservoir simulators, empirical models (e.g., Honarpour et al, 1982; Burdine, 1953), and special core analysis (Jerauld, 1997; Al-Gharbi et al, 2007) widely assume that $k_{\mathrm{rj}} \leq 1$. The present results indicate that this assumption will not be valid at moderate to strongly oil-wetting conditions.

\subsubsection{Apparent slippage}

A number of studies have reported apparent slippage of non-wetting phases in rock in the presence of a second, static wetting phase (Morrow et al, 1973; Pugh et al, 1991; Christensen and Tanino, 2017a; Berg et al, 2008, and references therein). Modelling the rock as a bundle of capillary tubes of radius $R_{1}=5 \sqrt{k / \phi}$ (Dullien, 1991) and applying the Poiseuille solution for steady, laminar flow, Christensen and Tanino (2017a) demonstrated that if the only impact of the residual oil is to reduce the cross-sectional area available to flow, $k_{\mathrm{rw}}\left(S_{\text {or }}\right)=\left(1-S_{\text {or }}\right)^{2}$. In the experiments considered presently, $k_{\mathrm{rw}}\left(S_{\mathrm{or}}\right)>\left(1-S_{\mathrm{or}}\right)^{2}$, viz. apparent slippage is observed, in all experiments at $\theta_{\mathrm{a}} \geq 125^{\circ}$ except for experiment C1 (Tables 4, 5).

Introducing an equivalent slip length, $\delta_{\mathrm{w}}$, to account for apparent slippage yields (Christensen and Tanino, 2017a):

$$
k_{\mathrm{rw}}\left(S_{\mathrm{or}}\right) \approx\left(1-S_{\mathrm{or}}\right)^{2}+4 \frac{\delta_{\mathrm{w}}}{R_{1}}\left(\frac{R_{2}}{R_{1}}\right)^{3},
$$

where $R_{1}-R_{2}$ is the thickness of the annular oil film at the tube wall; conservation of volume requires $R_{2} / R_{1}=\sqrt{1-S_{\mathrm{or}}} \cdot k_{\mathrm{rw}}\left(S_{\mathrm{or}}\right)$ derived presently translate to equivalent slip lengths of up to $\delta_{\mathrm{w}} \sim 200 \mathrm{~nm}$ (Fig. 5b), corroborating previous observations by Christensen and Tanino (2017a). 

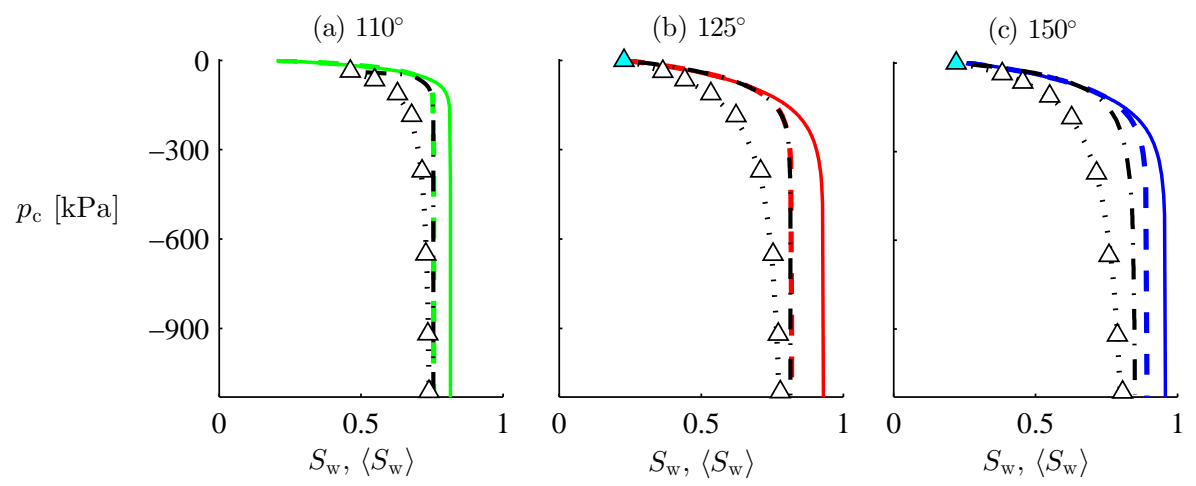

Fig. 6 Local $S_{\mathrm{w}}\left(p_{\mathrm{c}}\right)$ established by centrifuge as determined from the entire production curve (coloured lines) and as derived using Forbes (1994)'s solution of the second kind (black dashdotted) such that the corresponding core-averaged water saturation $\left\langle S_{\mathrm{w}}\right\rangle\left(p_{\mathrm{c}}\left(r_{1}+L\right)\right)$ (dotted line) best fits measured values at the end of each $\omega$ (open $\triangle$ ) at $\theta_{\mathrm{a}}=110^{\circ}$ (a), $125^{\circ}$ (b), and $150^{\circ}$ (c). Solid lines were derived by history matching using Eq. (13) to describe $k_{\mathrm{r}}\left(S_{\mathrm{w}}\right)$; dashed lines were derived using Eq. (18). Shaded $\boldsymbol{\Delta}$ in (b) and (c) depict $\left\langle S_{\mathrm{w}}\right\rangle(0)$ established by spontaneous imbibition in the same oil/brine/rock system by Christensen and Tanino (2017a) and Tanino and Blunt (2013), respectively.

\subsection{Forced imbibition capillary pressure}

We consider capillary pressure-saturation curves derived from centrifuge experiments and waterfloods separately.

\subsubsection{Centrifuge capillary pressure}

Fig. 6 presents best-fit capillary pressure-saturation curves derived by assuming equilibrium had been reached at the end of each $\omega$ and considering only the net oil production at each $\omega$ (black dash-dotted, Sec. 2.4.1) and by considering the full production curve using two different models to describe $k_{\mathrm{rj}}\left(S_{\mathrm{w}}\right)$ : a Corey (1954)type power law (solid lines) and LET correlations (dashed). All estimates of $S_{\mathrm{w}}\left(p_{\mathrm{c}}\right)$ display the canonical profile for imbibition capillary pressure: $S_{\mathrm{w}}$ increases monotonically with $\left|p_{\mathrm{c}}\right|$ at a rate that decreases as $\left|p_{\mathrm{c}}\right|$ increases until it reaches its asymptotic limit, viz. residual state.

At the largest $\theta_{\mathrm{a}}\left(=150^{\circ}\right)$, however, both LET correlation and Corey (1954)type power law yield optimized values of $S_{\text {or }}$ that are smaller than that predicted from the equilibrium analysis. Accordingly, the equilibrium analysis underestimates $S_{\mathrm{w}}$ at $\left|p_{\mathrm{c}}\right|>80 \mathrm{kPa}$, suggesting that oil was still draining from the cores at the end of each $\omega$ at larger $\omega$. There is some evidence of this in Fig. 2: while it is difficult to discern directly from the measured production, it is evident from the simulated production that at several $\left(\omega, \theta_{\mathrm{a}}\right)$, e.g., $\left(5830 \mathrm{rpm}, 150^{\circ}\right)$, equilibrium was not reached before $\omega$ was increased.

Fig. 7 presents $p_{\mathrm{c}}$ as a function of the re-scaled water saturation, $\widehat{S_{\mathrm{w}}}$, with the former non-dimensionalized using the classic Leverett- $J$ scaling. We considered 

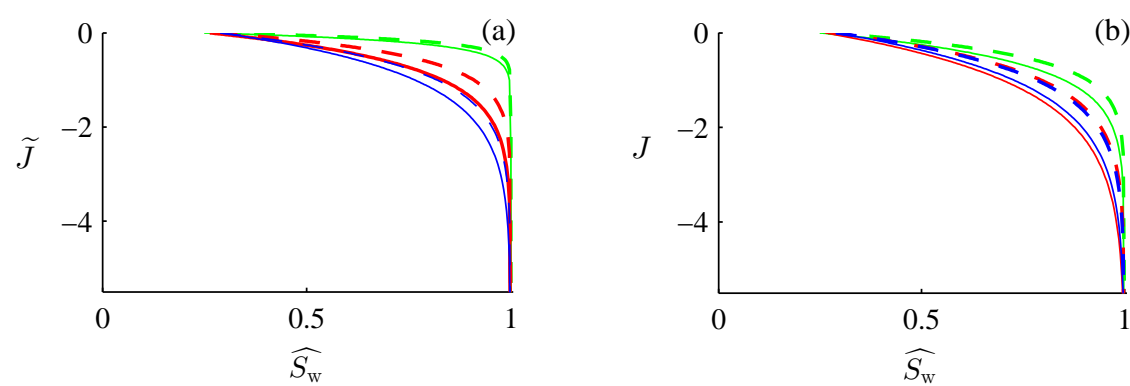

Fig. 7 Leverett- $J$ functions as given by Eqs. (27) (a) and (28) (b) plotted against the rescaled water saturation at $\theta_{\mathrm{a}}=110^{\circ}$ (green), $125^{\circ}$ (red), and $150^{\circ}$ (blue). See Table 4 for line definition.

two definitions:

$$
\widetilde{J}=\frac{p_{\mathrm{c}}}{\sigma} \sqrt{\frac{k}{\phi}}
$$

and

$$
J=\frac{p_{\mathrm{c}}}{\sigma|\cos \theta|} \sqrt{\frac{k}{\phi}} .
$$

As $\theta_{\mathrm{a}}$ increases, a larger $\left|p_{\mathrm{c}}\right|$ and $|\widetilde{J}|$ are needed to achieve a particular $\widehat{S_{\mathrm{w}}}$ (Fig. 7a), but dividing $\widetilde{J}$ by $\left|\cos \theta_{\mathrm{a}}\right|$ collapses the imbibition capillary pressure-saturation curves at $125^{\circ}$ (red lines) and $150^{\circ}$ (blue) onto a single curve (Fig. 7b). While $J\left(\widehat{S_{\mathrm{w}}}\right)$ for experiment $\mathrm{C} 2\left(\theta_{\mathrm{a}}=110^{\circ}\right)$ deviates from the other two $\theta_{\mathrm{a}}$, it will coincide with the other two curves if the value of $\theta_{\mathrm{a}}$ in Eq. (28) is taken to be $\theta_{\mathrm{a}}=100^{\circ}$ instead of $110^{\circ}$. A deviation of $\pm 5^{\circ}$ falls within typical variability of bulk contact angle measurements, and the present results suggest that bulk contact angle measurements on flat substrates are a good proxy for the true, in situ contact angles within the pore space of rock for the purpose of scaling the capillary pressure curve.

\subsubsection{Waterflood capillary pressure}

Capillary pressure-saturation curves derived from waterfloods are presented in Fig. 8 in non-dimensionalized form $J\left(S_{\mathrm{w}}\right)$ (black lines). At all $\theta_{\mathrm{a}}$ considered, the core with the larger $k / \phi$ (dash-dotted line) has a smaller $S_{\text {or }}$ and, accordingly, $J\left(S_{\mathrm{w}}\right)$ is shifted to higher $S_{\mathrm{w}}$. While the same trend has been documented under uniformly water-wet conditions (e.g., Tanino and Blunt, 2012), the pore-scale displacement mechanism giving rise to the trend is not likely to be the same.

Next we consider the $\theta_{\mathrm{a}}$ dependence of the fitting parameters in Eq. (19). As in the centrifuge experiments, the magnitude of the $\widetilde{J}\left(S_{\mathrm{w}}\right)$ curve increases with $\theta_{\mathrm{a}}$ such that $\widetilde{J}^{*}$ increases monotonically with $\theta_{\text {a }}$ (Fig. 9a). However, unlike centrifugederived $p_{\mathrm{c}}\left(S_{\mathrm{w}}\right)$, the $\theta_{\mathrm{a}}$ dependence is not fully captured by the Leverett- $J$ scaling (solid line, Fig. 9a). As expected, $\beta$ decreases with increasing $\theta_{\mathrm{a}}: \beta \approx 100$ at the smallest $\theta_{\mathrm{a}}=110^{\circ}$, then decreases rapidly to $\beta \approx 4.5$ at $\theta_{\mathrm{a}}=125^{\circ}$ above which it is only a weakly decreasing function of $\theta_{\mathrm{a}}$ (Fig. 9c). 

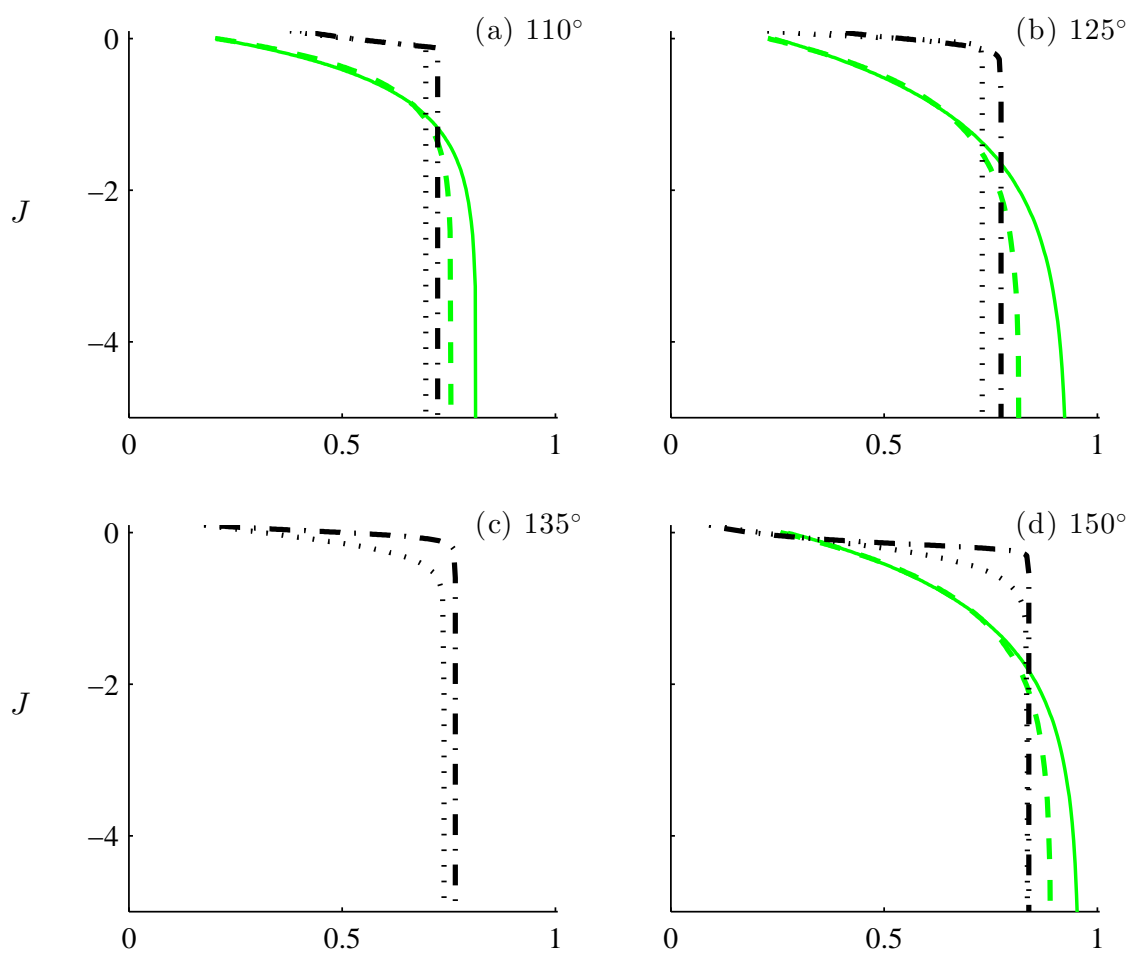

$S_{\mathrm{w}}$

$S_{\mathrm{W}}$

Fig. 8 Leverett- $J$ function at $\theta_{\mathrm{a}}=110^{\circ}$ (a), $125^{\circ}$ (b), $135^{\circ}$ (c), and $150^{\circ}$ (d) derived from centrifuge (green lines) and waterflood (black dotted, dash-dotted lines) experiments. Green solid lines were derived by history matching using Eq. (13) to describe $k_{\mathrm{r}}\left(S_{\mathrm{w}}\right)$; dashed lines were derived using Eq. (18). For each $\theta_{\mathrm{a}}$, the dash-dotted line depicts the waterflood on the core with the larger $k / \phi(\mathrm{D}, \mathrm{V}, \mathrm{AH}, \mathrm{N})$. Recall that centrifuge experiments were not performed at $\theta_{\mathrm{a}}=135^{\circ}$.

$\widehat{S_{\mathrm{w}}}(0)$ corresponds to $S_{\mathrm{w}}$ that would be achieved by spontaneous imbibition alone (Fig. $9 \mathrm{~b}$ ). At $\theta_{\mathrm{a}}<130^{\circ}, \widehat{S_{\mathrm{w}}}(0) \approx 70 \%$ of the maximum water saturation enters the rock by spontaneous imbibition (circles), indicating that the local, in situ contact angle was $<90^{\circ}$ in a significant fraction of pores. From $\theta_{\mathrm{a}}=125^{\circ}$ to $150^{\circ}, \widehat{S_{\mathrm{w}}}(0)$ decreases rapidly with increasing $\theta_{\mathrm{a}}$, indicating that the fraction of hydrophilic pores decreases rapidly with increasing $\theta_{\mathrm{a}}$. A number of factors can cause the in situ contact angle to deviate from bulk contact angles measured on mineralogically representative, flat substrates including confinement (e.g., Li et al, 2014), contact line velocity (e.g., Li et al, 2013; Min et al, 2011), and surface roughness (e.g., AlRatrout et al, 2018; Morrow, 1975; Bowden et al, 2016). Further insight requires a systematic study of each of these factors. 

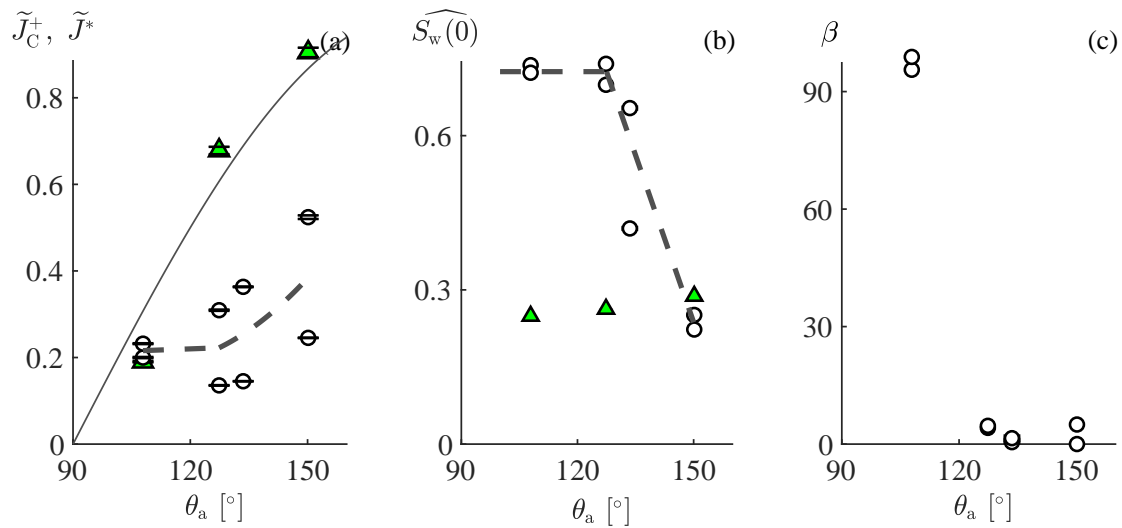

Fig. 9 Optimized values of $\widetilde{J}^{*}, \widetilde{J}_{\mathrm{C}}^{+}(\mathrm{a}), \widehat{S_{\mathrm{w}}}\left(p_{\mathrm{c}}=0\right)(\mathrm{b})$, and $\beta$ (c) as determined from centrifuge (green $\mathbf{\Lambda}$; see Table 4 for marker definition) and waterfloods (open circles). Recall that the analytical function used to describe $p_{\mathrm{c}}\left(S_{\mathrm{w}}\right)$ in the simulations of centrifuge experiments does not include the parameter $\beta$. Solid line in (a) is $\widetilde{J}=\left|\cos \theta_{\mathrm{a}}\right|$; dashed lines are intended as a guide to the eye. Horizontal bars depict the standard error of the mean in the measured $\theta_{\mathrm{a}}$; where the bars are not visible they are smaller than the marker size.

\subsubsection{Non-equilibrium (dynamic) effects}

Interestingly, $|\widetilde{J}|$ required to establish a particular $S_{\mathrm{w}}$ is larger under centrifuge than waterflood at all $\theta_{\mathrm{a}}$ considered (Fig. 8). One explanation for such a trend is dynamic effects, which manifests as a difference between the true (dynamic) $p_{\mathrm{c}}\left(S_{\mathrm{w}}\right)$ and $p_{\mathrm{c}}\left(S_{\mathrm{w}}\right)$ at equilibrium, $p_{\mathrm{c}}^{\mathrm{e}}$. A simple and widely used model defines an empirical constant of proportionality, $\tau(>0)$, to relate the difference between the two capillary pressures to the rate of change of $S_{\mathrm{w}}$ (Manthey et al 2008 and references therein):

$$
p_{\mathrm{c}}\left(S_{\mathrm{w}}\right)-p_{\mathrm{c}}^{\mathrm{e}}\left(S_{\mathrm{w}}\right)=-\tau \frac{\partial S_{\mathrm{w}}}{\partial t}
$$

During imbibition, $\partial S_{\mathrm{w}} / \partial t>0$ and, consequently, Eq. (29) implies that $p_{\mathrm{c}}\left(S_{\mathrm{w}}\right)<$ $p_{\mathrm{c}}^{\mathrm{e}}\left(S_{\mathrm{w}}\right)$, viz. dynamic effects cause $p_{\mathrm{c}}\left(S_{\mathrm{w}}\right)$ to shift towards more negative values. This in turn implies that if the observed difference in $p_{\mathrm{c}}\left(S_{\mathrm{w}}\right)$ between the present centrifuge experiments and waterfloods is a manifestation of dynamic effects, then those effects - hence $\tau \cdot \partial S_{\mathrm{w}} / \partial t$ - would have been larger in the former.

The relative importance of dynamic and equilibrium capillary forces is characterized by the dimensionless parameter (Manthey et al, 2008)

$$
\mathrm{DyC}=\frac{\tau u_{\mathrm{c}}}{p_{\mathrm{cc}} l_{\mathrm{c}} \phi}
$$

where $\left(l_{\mathrm{c}}, u_{\mathrm{c}}, p_{\mathrm{cc}}\right)$ are the characteristic length, velocity, and capillary pressure, respectively. In the experiments considered presently, DyC is smaller for the centrifuge experiments than the waterfloods at all $\theta_{\mathrm{a}}$ (Fig. S4) ${ }^{10}$, suggesting that the deviation in $\widetilde{J}$ between centrifuge and waterfloods is not a manifestation of dynamic effects. Further insight requires an extension of the present analysis to

\footnotetext{
10 Details of the calculation can be found in Supplementary Material Text S6.
} 


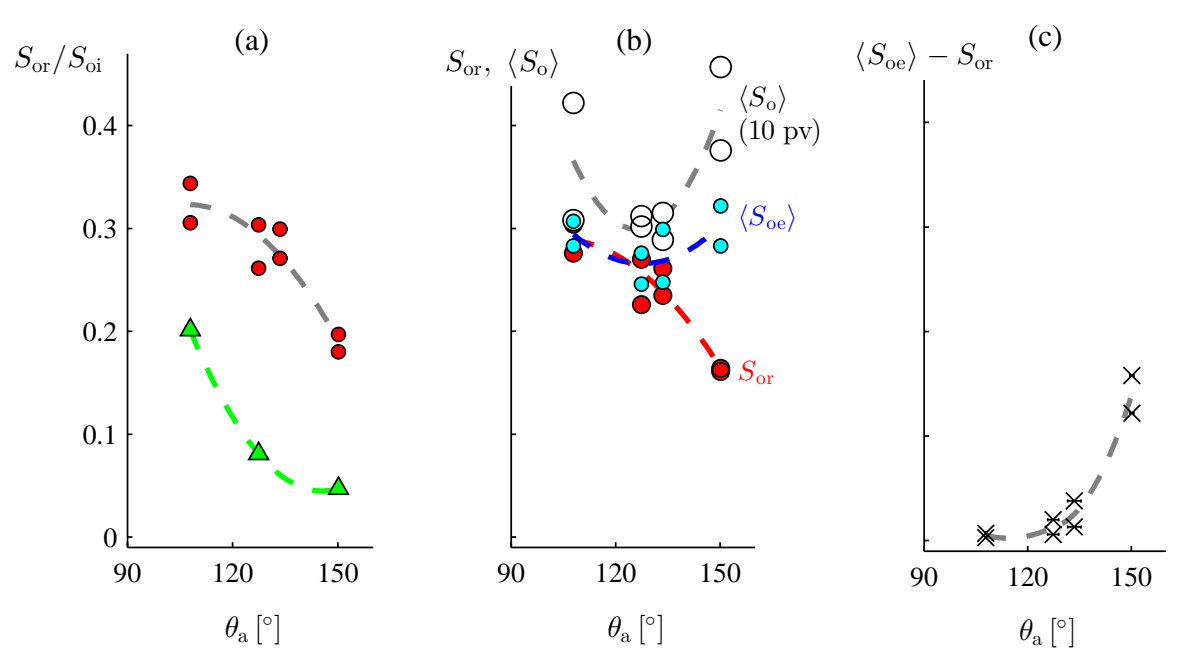

Fig. 10 Residual oil saturation as derived by history matching to centrifuge experiments (green $\boldsymbol{\Delta}$ ) and from waterflood data (red $\bullet$ ), core-averaged oil saturation at $\widetilde{t}=10$ (open $\circ)$ and 100000 (cyan $\bullet$ ), and the difference between equilibrium core-averaged oil saturation and $S_{\text {or }}(\times)$. Horizontal bars are standard errors of the mean of contact angle measurements; where the bars are not visible they are smaller than the marker size. Dashed lines are intended as a guide to the eye.

larger $\omega$ (and hence Bo) and $U_{\mathrm{w}}$ (and hence Ca) and a systematic investigation involving additional centrifuge and waterflood experiments in different rocks.

Regardless of the physics that gives rise to it, the systematic deviation indicates that $p_{\mathrm{c}}\left(S_{\mathrm{w}}\right)$ is not unique even for the same oil/brine/rock system, which in turn implies that the conventional approach of using independently measured $\widetilde{J}\left(\widehat{S_{\mathrm{w}}}\right)$ (such as one measured by centrifuge) as a fixed parameter and adjusting only $k_{\mathrm{r}}\left(S_{\mathrm{w}}\right)$ and $S_{\text {or }}$ to history-match to coreflood data is not be valid under certain conditions. Similar conclusions were drawn by Yaralidarani and Shahverdi (2018) who also observed significant deviation between centrifuge experiments and corefloods in oil/gas/tight carbonate systems.

\subsection{Residual saturation}

Fig. 10a presents residual oil saturation as determined by history matching to centrifuge experiments (green $\boldsymbol{\Delta}$ ) and waterfloods (red $\bullet$ ). $S_{\text {or }}$ decreases monotonically with increasing $\theta_{\mathrm{a}}$ in both sets of experiments, consistent with laboratory measurements by Owens and Archer (1971) and pore network simulations by Ryazanov et al (2009). This dependence can be explained as follows. During forced imbibition in mixed-wet rock, oil drains through connected films (or oil layers) on oil-wet patches of the grain surface (Salathiel, 1973; Singh et al, 2016; Iglauer et al, 2012). If these oil films become more stable with increasing $\theta_{\mathrm{a}}$ as proposed by, e.g., Ryazanov et al (2009), oil would remain connected and drain to lower saturations at larger $\theta_{\mathrm{a}}$. 
The negative correlation between $S_{\text {or }}$ and $\theta_{\mathrm{a}}$ is in sharp contrast to the nonmonotonic dependence of core-averaged oil saturation, $\left\langle S_{\mathrm{o}}\right\rangle$, after $\widetilde{t} \geq 10$ (Fig. 10b, open circles) which persists to equilibrium (cyan $\bullet$ ). Two factors contribute to the discrepancy between core-averaged oil saturation and $S_{\text {or }}$ : premature termination of the waterflood and capillary end effects. The difference between $\left\langle S_{\mathrm{o}}\right\rangle(t)$ and the core-averaged oil saturation at equilibrium, $\left\langle S_{\mathrm{oe}}\right\rangle$, is a measure of the impact of premature termination of waterflood. Terminating the waterflood at, say, $\widetilde{t}=10$ can result in $\left\langle S_{\mathrm{o}}\right\rangle$ that is up to $20 \%$ of the pore volume larger than its equilibrium value. Analogously, the difference between $\left\langle S_{\mathrm{oe}}\right\rangle$ and $S_{\text {or }}$ is a direct measure of capillary end effects. $\left\langle S_{\mathrm{oe}}\right\rangle-S_{\text {or }}$ varies between $\left\langle S_{\mathrm{oe}}\right\rangle-S_{\mathrm{or}}=0.3$ and $20 \mathrm{pv} \%$ and, as expected, increases monotonically with $\theta_{\mathrm{a}}($ Fig. $10 \mathrm{c}, \times)$. These values are in good agreement with those reported by Masalmeh (2012). While these values of $\left\langle S_{\text {oe }}\right\rangle-S_{\text {or }}$ may appear small, we emphasize that they are in terms of fractional pore volume. Indeed, $\left\langle S_{\mathrm{oe}}\right\rangle-S_{\mathrm{or}}=12 \mathrm{pv} \%$ and $16 \mathrm{pv} \%$ for the two waterfloods at $\theta_{\mathrm{a}}=150^{\circ}$, which correspond to an error in $S_{\text {or }}$ of $\left(\left\langle S_{\mathrm{oe}}\right\rangle-S_{\text {or }}\right) / S_{\text {or }}=76 \%$ and $96 \%$, respectively.

\subsection{Uncertainty analysis}

\subsubsection{Sensitivity to parametric model for $k_{r}\left(S_{w}\right)$}

We compare the inversion of the centrifuge experiments using LET correlations and Corey (1954)-type power law (Sec. 2.4.2). Both Corey (1954)-type power law and LET correlations yield good agreement with measured cumulative oil production (Fig. 2). The comparable agreement is somewhat surprising, given that the use of Eq. (18) involves twelve fitting parameters instead of the seven needed for Eq. (13).

Next we consider the optimized $k_{\mathrm{w}}\left(S_{\mathrm{w}}\right)$ and $p_{\mathrm{c}}\left(S_{\mathrm{w}}\right)$ (Figs. 4, 6). Compared to Corey (1954)-type functions (Fig. 4, solid lines), optimization using LET correlations (dashed) yield significantly larger $k_{\mathrm{rw}}\left(S_{\mathrm{or}}\right)$ at $S_{\mathrm{w}} \gtrsim 0.5$ at all $\theta_{\mathrm{a}}$; at $\theta_{\mathrm{a}}=125^{\circ}$ in particular, this discrepancy spans the entire range $0<S_{\mathrm{w}} \leq 1-S_{\text {or }}$ (Fig. $4 \mathrm{~b}$ ). Interestingly, the optimized Corey (1954)-type functions are in better agreement with the LET correlations fitted to the waterfloods (dash-dotted, dotted lines).

The use of LET correlations consistently yields a larger $S_{\text {or }}$ than Corey (1954)type power law (Table 4 ) and, consequently, the associated $p_{\mathrm{c}}\left(S_{\mathrm{w}}\right)$ is closer to that derived from the equilibrium analysis at all $\theta_{\mathrm{a}}$ (Fig. 6). Indeed, at $\theta_{\mathrm{a}}=110^{\circ}$ and $125^{\circ}$, there is excellent agreement between $p_{\mathrm{c}}\left(S_{\mathrm{w}}\right)$ derived using LET correlations (Fig. 6, dashed) and the equilibrium analysis.

\subsubsection{Sensitivity to upper limit of $k_{r w}\left(S_{w}\right)$}

We now compare the inversion of the three experiments at $\theta_{\mathrm{a}}=150^{\circ}$ with water relative permeabilities restricted to $k_{\mathrm{rw}}\left(S_{\mathrm{or}}\right) \leq 1$. Good agreement between data and simulation is achieved even with this additional constraint on $k_{\mathrm{rw}}\left(S_{\mathrm{or}}\right)$ (Figs. S5, S6). However, a significant fraction of the optimized parameters 3 parameters out of 7 for experiment C3, 7 out of 12 for N, and 5 out of 12 for TB/I coincide with the limits imposed on them (cf. Tables 2, 2.5.1), suggesting that they would be bigger/smaller if the limits were relaxed. Given that the limits are based on physical reasoning and defined conservatively, the history match with a even 

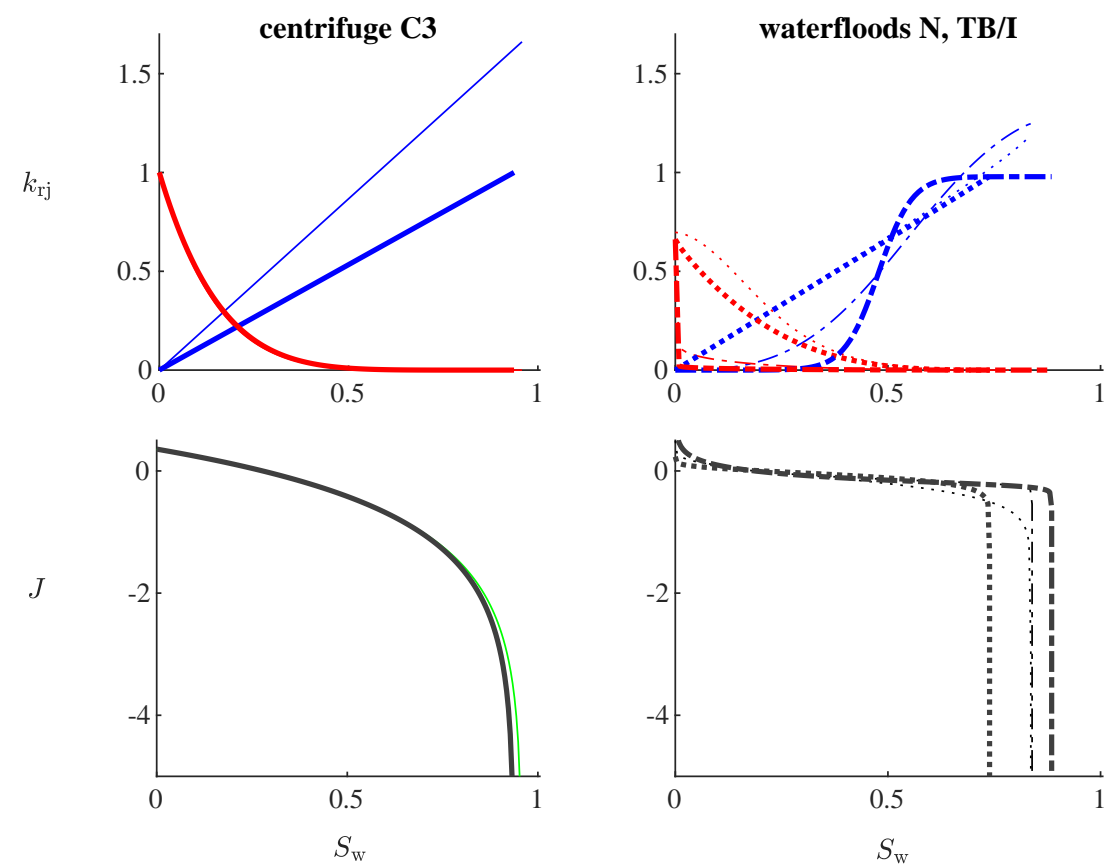

Fig. 11 Optimized oil (red) and brine (blue) relative permeabilities (top row, thick lines) and $J\left(S_{\mathrm{w}}\right)$ (bottom row, thick grey lines) derived from centrifuge C3 (solid lines), waterflood $\mathrm{N}$ (dash-dotted), and waterflood TB/I (dotted) by imposing $k_{\mathrm{rw}}\left(S_{\mathrm{or}}\right) \leq 1$. Superposed are corresponding best-fit functions from Figs. 4 and 8 (thin lines).

weaker restriction on the parameter ranges would yield unrealistic parameters. Thus inversion with $k_{\mathrm{rw}}\left(S_{\mathrm{or}}\right) \leq 1$ imposed does not yield a satisfactory solution despite the apparent agreement between experiment and simulation.

The best-fit $k_{\mathrm{r}}\left(S_{\mathrm{w}}\right)$ and $J\left(S_{\mathrm{w}}\right)$ are presented in Fig. 11 (thick lines). For the centrifuge experiment, the optimized $k_{\mathrm{rw}}\left(S_{\mathrm{or}}\right)$ is reduced from $k_{\mathrm{rw}}\left(S_{\mathrm{or}}\right)=1.661$ to 1 , but this has limited impact on $J\left(S_{\mathrm{w}}\right), k_{\mathrm{ro}}\left(S_{\mathrm{w}}\right)$, and $S_{\text {or }}$ (see Table $\mathrm{S} 4$ for optimized parameters). In contrast, the inversion of the waterfloods is more sensitive to the constraint on $k_{\mathrm{ro}}\left(S_{\mathrm{w}}\right)$ (Fig. 11, right column). This difference in sensitivity to parameter range is as expected: each centrifuge experiment comprise measurements at eight rotation speeds, whereas each waterflood corresponds to one injection rate, $U_{\mathrm{w}}$, only. Nonetheless, $k_{\mathrm{r}}\left(S_{\mathrm{w}}\right)$ and $J\left(S_{\mathrm{w}}\right)$ averaged over the two waterfloods is less sensitive. For example, $S_{\text {or }}$ only increased by $2.5 \mathrm{pv} \%$ from $S_{\text {or }}=0.16$ to 0.19 , the average $k_{\text {ro }}(0)$ decreased by only 0.02 from $k_{\text {ro }}(0)=0.68$ to 0.66 , and the average $S_{\mathrm{w}}(0)$ remained the same at 0.20 .

Moreover, key trends with respect to $\theta_{\mathrm{a}}$ are conserved: $k_{\mathrm{rw}}\left(S_{\mathrm{or}}\right)$ increases, $\delta_{\mathrm{w}}$ increases, $S_{\text {or }}$ decreases and - for waterfloods only - $S_{\mathrm{w}}(0)$ decreases with increasing $\theta_{\mathrm{a}}$. Apparent slippage is observed even with $k_{\mathrm{rw}}$ constrained to $\leq 1$ (Table S4), although the equivalent slip lengths are smaller $\left(\delta_{\mathrm{w}} \approx 25,80\right.$, and $95 \mathrm{~nm}$ for experiments $\mathrm{C} 3, \mathrm{~N}$, and TB/I, respectively). 


\section{Conclusions}

We presented forced imbibition capillary pressure and relative permeability curves for mixed-wet Indiana limestone under different mixed wettability conditions. The main findings, under conditions considered presently, are:

- At all $\theta_{\mathrm{a}}$ considered, a larger (more negative) capillary pressure is required to establish a particular $S_{\mathrm{w}}$ during centrifuge than waterflood.

- The magnitude of the capillary pressure required to establish a particular $S_{\mathrm{w}}$ increases with $\theta_{\mathrm{a}}$. This dependence is captured by the classic Leverett- $J$ function for centrifuge experiments only within experimental uncertainty.

- End-point water permeability increases as the oil/water/rock system becomes more oil-wetting.

- Apparent slippage, viz. $k_{\mathrm{rw}}\left(S_{\mathrm{or}}\right)>\left(1-S_{\mathrm{or}}\right)^{2}$, is observed at $\theta_{\mathrm{a}} \geq 125^{\circ}$.

- $S_{\text {or }}$ decreases monotonically with increasing contact angle from $\theta_{\mathrm{a}}=110^{\circ}$ to $150^{\circ}$.

- Capillary end effects elevate the core-averaged equilibrium oil saturation established by forced imbibition from maximum $S_{\text {oi }}$ by 0 to $15 \%$ of the pore volume above $S_{\text {or }}$, with the deviation increasing with increasing $\theta_{\mathrm{a}}$.

- With realistic $k_{\mathrm{rw}}\left(S_{\mathrm{w}}\right), k_{\mathrm{ro}}\left(S_{\mathrm{w}}\right)$, and $p_{\mathrm{c}}\left(S_{\mathrm{w}}\right)$ curves, $S_{\text {or }}$ that decreases monotonically with contact angle can still give rise to a non-monotonic core-averaged oil saturation.

Huang and Honarpour (1998) noted that capillary end effects were most pronounced when oil displaces water in water-wet cores and gas displaces oil. The discrepancy between waterflood $S_{\text {or }}$ and core-averaged end-point saturation indicates that capillary end effects can also be significant when water displaces oil in mixed-wet rock, at sufficiently large $\theta_{\mathrm{a}}$, and highlights the importance of using simulation to interpret coreflood data under capillary-dominated conditions.

Acknowledgements MC was supported by the University of Aberdeen College of Physical Sciences studentship. The authors gratefully acknowledge CYDAREX for providing an evaluation license for their software CYDAR ${ }^{\mathrm{TM}}$, Koon-Yang Lee for the $n$-decane/brine static contact angle measurements on calcite (Supplementary Material S3), and Steffen Berg for his insightful comments and suggestions as a reviewer for conference paper Christensen and Tanino 2018 on which this paper builds. Finally, the authors thank the three anonymous reviewers for their detailed comments.

All data used in this study are available from the corresponding author on reasonable request. In addition, the centrifuge data generated during this study are included as a Excel spreadsheet in the supplementary materials for this published article. One set of mercury injection capillary pressure measurements by Tanino and Blunt (2012) analyzed in Text S2 are available in the Mendeley data repository, https://data.mendeley.com/datasets/9f4898jfr9/1.

\section{References}

Al-Gharbi MS, Jing X, Kraaijveld M, Hognestad JB, Udeh PO (2007) SCAL relative permeability measurements and analyses for a cluster of fields in South Oman. In: Proc., International Petroleum Technology Conference, 46 Dec., International Petroleum Technology Conference, Dubai, UAE, DOI 10.2523/IPTC-11415-MS 
Alhammadi AM, AlRatrout A, Singh K, Bijeljic B, Blunt MJ (2017) In situ characterization of mixed-wettability in a reservoir rock at subsurface conditions. Scientific Reports 7:1-9, DOI 10.1038/s41598-017-10992-w

AlRatrout A, Raeini AQ, Bijeljic B, Blunt MJ (2017) Automatic measurement of contact angle in pore-space images. Adv Water Resour 109:158 - 169, DOI 10.1016/j.advwatres.2017.07.018

AlRatrout A, Blunt MJ, Bijeljic B (2018) Wettability in complex porous materials, the mixed-wet state, and its relationship to surface roughness. Proc Nat Academy Sci 115(36):8901-8906, DOI 10.1073/pnas.1803734115

Amott E (1959) Observations relating to the wettability of porous rock. Trans AIME 216:156162

Anderson WG (1987) Wettability literature survey part 4: Effects of wettability on capillary pressure. J Petrol Technol 39(10):1283-1300, DOI 10.2118/15271-PA

Anggraini L (2013) Buckley-Leverett analysis of waterflood oil recovery from mixed-wet rock. Master's thesis, University of Aberdeen, Scotland, UK

Ayappa KG, Davis HT, Davis EA, Gordon J (1989) Capillary pressure: centrifuge method revisited. AIChE J 35(3):365-372, DOI 10.1002/aic.690350304

Bear J (1988) Dynamics of Fluids in Porous Media. Dover Publications, Inc., New York

Berg S, Cense AW, Hofman JP, Smits RMM (2008) Two-phase flow in porous media with slip boundary condition. Transport Porous Med 74(3):275-292

Bowden SA, Tanino Y, Akamairo B, Christensen M (2016) Recreating mineralogical petrographic heterogeneity within microfluidic chips: assembly, examples, and applications. Lab Chip 16:4677-4681, DOI 10.1039/C6LC01209D

Brooks RH, Corey AT (1964) Hydraulic properties of porous media. Hydrology Papers 3, Colorado State University, Fort Collins, Colorado

Brooks RH, Corey AT (1966) Properties of porous media affecting fluid flow. Journal of the Irrigation and Drainage Division 92(2):61-90

Burdine NT (1953) Relative permeability calculations from pore size distribution data. J Petrol Technol 5(3):71-78, DOI 10.2118/225-G

Chen J, Hopmans J, Grismer M (1999) Parameter estimation of two-fluid capillary pressuresaturation and permeability functions. Adv Water Resour 22(5):479 493, DOI 10.1016/S0309-1708(98)00025-6

Chen J, Hirasaki G, Flaum M (2006) NMR wettability indices: Effect of OBM on wettability and NMR responses. J Petrol Sci Eng 52(1):161 - 171, DOI 10.1016/j.petrol.2006.03.007

Christensen M (2018) Impact of wettability on two-phase flow in oil/water/carbonate rock systems. PhD thesis, University of Aberdeen, Aberdeen, UK

Christensen M, Tanino Y (2017a) Enhanced permeability due to apparent oil/brine slippage in limestone and its dependence on wettability. Geophys Res Lett 44(12), DOI 10.1002/2017GL073603

Christensen M, Tanino Y (2017b) Waterflood oil recovery from mixed-wet limestone: dependence on contact angle. Energy Fuel 31(2):1529-1535, DOI 10.1021 /acs.energyfuels.6b03249

Christensen M, Tanino Y (2018) Residual oil saturation under mixed-wet conditions: optimal wettability revisited. In: Proc., International Symposium of the Society of Core Analysts, 27 - 30 Aug., Society of Core Analysts, Trondheim, Norway, SCA2018-011 
Corey AT (1954) The interrelation between gas and oil relative permeabilities. Prod Mon 19:3841

CYDAREX (2017) CYDAR-SCAL User-manual. CYDAREX

Duchenne S, de Loubens R, Petitfrere M, Joubert T (2015) Modeling and simultaneous history-matching of multiple WAG coreflood experiments at reservoir conditions. In: Proc., Abu Dhabi International Petroleum Exhibition and Conference, 9 - 12 Nov., Society of Petroleum Engineers, Abu Dhabi, UAE, SPE177531-MS, DOI 10.2118/177531-MS

Dullien FAL (1991) Porous Media. Fluid Transport and Pore Structure, 2nd edn. Academic Press, Inc., San Diego, CA

Dwarakanath V, Jackson RE, Pope GA (2002) Influence of wettability on the recovery of NAPLs from alluvium. Environ Sci Tech 36(2):227-231, DOI $10.1021 / \mathrm{es} 011023 \mathrm{w}$

Forbes P (1994) Simple and accurate methods for converting centrifuge data into drainage and imbibition capillary pressure curves. Log Analyst 35(4):31-53

Gharbi O, Blunt MJ (2012) The impact of wettability and connectivity on relative permeability in carbonates: A pore network modeling analysis. Water Resources Research 48(12), DOI 10.1029/2012WR011877

Hassenkam T, Skovbjerg LL, Stipp SLS (2009) Probing the intrinsically oil-wet surfaces of pores in north sea chalk at subpore resolution. PNAS 106(15):60716076, DOI 10.1073/pnas.0901051106

Honarpour M, Koederitz LF, Harvey AH (1982) Empirical equations for estimating two-phase relative permeability in consolidated rock. J Petroleum Technol 34(12):2905-2908, DOI 10.2118/9966-PA

Huang DD, Honarpour MM (1998) Capillary end effects in coreflood calculations. J Petrol Sci Eng 19(1):103 - 117, DOI 10.1016/S0920-4105(97)00040-5

Huang DM, Sendner C, Horinek D, Netz RR, Bocquet L (2008) Water slippage versus contact angle: a quasiuniversal relationship. Phys Rev Lett 101(22):226,101, DOI 10.1103/PhysRevLett.101.226101

Humphry KJ, Suijkerbuijk BMJM, van der Linde HA, Pieterse SGJ, Masalmeh SK (2013) Impact of wettability on residual oil saturation and capillary desaturation curves. In: Proc., International Symposium of the Society of Core Analysts, 1619 Sept., Society of Core Analysts, Napa Valley, CA, SCA2013-025

Iglauer S, Ferno MA, Shearing P, Blunt MJ (2012) Comparison of residual oil cluster size distribution, morphology and saturation in oil-wet and water-wet sandstone. J Colloid Interf Sci 375(1):187 - 192, DOI 10.1016/j.jcis.2012.02.025

Jadhunandan PP, Morrow NR (1995) Effect of wettability on waterflood recovery for crude-oil/brine/rock systems. SPE Reservoir Eng 10(1):40-46, DOI 10.2118/22597-PA

Jerauld G (1997) Prudhoe bay gas/oil relative permeability. SPE Res Eng 12(1):66-73, DOI 10.2118/35718-PA

Jerauld GR, Rathmell JJ (1997) Wettability and relative permeability of Prudhoe Bay: a case study in mixed-wet reservoirs. SPE Reservoir Eng 12(1):58-65, DOI 10.2118/28576-PA

Joekar-Niasar V, Hassanizadeh SM, Leijnse A (2008) Insights into the relationships among capillary pressure, saturation, interfacial area and relative permeability using pore-network modeling. Transp Porous Med 74(2):201-219, DOI $10.1007 / \mathrm{s} 11242-007-9191-7$ 
Kennedy HT, Burja EO, Boykin RS (1955) An investigation of the effects of wettability on oil recovery by water flooding. J Phys Chem 59(9):867-869, DOI $10.1021 / \mathrm{j} 150531 \mathrm{a} 015$

Kovscek AR, Wong H, Radke CJ (1993) A pore-level scenario for the development of mixed wettability in oil reservoirs. AIChE J 39(6):1072 - 1085, DOI 10.1002/aic.690390616

Li X, Fan X, Askounis A, Wu K, Sefiane K, Koutsos V (2013) An experimental study on dynamic pore wettability. Chemical Engineering Science 104:988 - 997, DOI $10.1016 /$ j.ces.2013.10.026

Li X, Fan X, Brandani S (2014) Difference in pore contact angle and the contact angle measured on a flat surface and in an open space. Chem Eng Sci 117:137 - 145, DOI 10.1016/j.ces.2014.06.024

Liu Y, Buckley JS (1997) Evolution of wetting alteration by adsorption from crude oil. SPE Formation Eval pp 5-11, DOI 10.2118/28970-PA

Lomeland F, Ebeltoft E, Thomas WH (2005) A new versatile relative permeability correlation. In: Proc., International Symposium of the Society of Core Analysts, 21-25 Aug., Toronto, Canada, SCA2005-32

Lorentz PB, Donaldson EC, Thomas RD (1974) Use of centrifugal measurements of wettability to predict oil recovery. In: Technical Report, 7873, USBM, Bartlesville Energy Technology Center

Manthey S, Hassanizadeh SM, Helmig R, Hilfer R (2008) Dimensional analysis of two-phase flow including a rate-dependent capillary pressuresaturation relationship. Adv Water Resour 31(9):1137 - 1150, DOI 10.1016/j.advwatres.2008.01.021

Masalmeh SK (2012) Impact of capillary forces on residual oil saturation and flooding experiments for mixed to oil-wet carbonate reservoirs. In: Proc., International Symposium of the Society of Core Analysts, 27-30 Aug., Aberdeen, UK, SCA2012-11

Min Q, Duan YY, Wang XD, Liang ZP, Si C (2011) Does macroscopic flow geometry influence wetting dynamic? J Colloid Interf Sci 362(1):221 - 227, DOI $10.1016 /$ j.jcis.2011.06.029

Morrow NR (1975) The effects of surface roughness on contact angle with special reference to petroleum recovery. J Can Petrol Technol 14(4):42-53, DOI 10.2118/75-04-04

Morrow NR, Mason G (2001) Recovery of oil by spontaneous imbibition. Curr Opin Colloid Inter Sci 6(4):321 - 337, DOI 10.1016/S1359-0294(01)00100-5

Morrow NR, Cram PJ, McCaffery FG (1973) Displacement studies in dolomite with wettability control by octanoic acid. Soc Petrol Eng J 13(4):221-232, DOI 10.2118/3993-PA

Øren PE, Bakke S, Arntzen OJ (1998) Extending predictive capabilities to network models. Soc Petrol Eng J 3(4):324-336, DOI 10.2118/52052-PA

Owens WW, Archer DL (1971) The effect of rock wettability on oil-water relative permeability relationships. J Petrol Technol 23(7):873-878, DOI 10.2118/3034PA

Powers SE, Tamblin ME (1995) Wettability of porous media after exposure to synthetic gasolines. J Contam Hydrol 19(2):105-125, DOI 10.1016/01697722(95)00008-J

Powers SE, Anckner WH, Seacord TF (1996) Wettability of NAPL-contaminated sands. J Environ Eng 122(10):889-896, DOI 10.1061/(ASCE)0733- 
9372(1996)122:10(889)

Pugh VJ, Thomas DC, Gupta SP (1991) Correlations of liquid and air permeabilities for use in reservoir engineering studies. Log Analyst 32:493 - 497

Romanello L (2015) Impact of wettability on relative permeability. Master's thesis, University of Aberdeen, Aberdeen, UK

Ryazanov AV, van Dijke MIJ, Sorbie KS (2009) Two-phase pore-network modelling: existence of oil layers during water invasion. Transp Porous Media 80:7999, DOI 10.1007/s11242-009-9345-x

Ryazanov AV, van Dijke MIJ, Sorbie KS (2010) Pore-network prediction of residual oil saturation based on oil layer drainage in mixed-wet systems. In: Proc., SPE Improved Oil Recovery Symposium, 24-28 April, Society of Petroleum Engineers, Oklahoma, USA, DOI 10.2118/129919-MS

Salathiel RA (1973) Oil recovery by surface film drainage in mixed-wettability rocks. Soc Petrol Eng J 25(10):1216-1224, DOI 10.2118/4104-PA

Scanziani A, Singh K, Blunt MJ, Guadagnini A (2017) Automatic method for estimation of in situ effective contact angle from X-ray micro tomography images of two-phase flow in porous media. J Colloid Interf Sci 496:51-59, DOI $10.1016 /$ j.jcis.2017.02.005

Singh K, Bijeljic B, Blunt MJ (2016) Imaging of oil layers, curvature, and contact angle in a mixed-wet and a water-wet carbonate rock. Water Resour Res 52(3):1716-1728, DOI 10.1002/2015WR0180072

Skjaeveland SM, Siqveland LM, Kjosavik A, Thomas WLH, Virnovsky GA (2000) Capillary pressure correlation for mixed-wet reservoirs. SPE Reservoir Eval Eng 3(1):60 - 67, DOI 10.2118/60900-PA

Subbey S, Monfared H, Christie M, Sambridge M (2006) Quantifying uncertainty in flow functions derived from SCAL data. Transp Porous Media 65(2):265-286, DOI $10.1007 / \mathrm{s} 11242-005-5998-2$

Tanino Y, Blunt MJ (2012) Capillary trapping in sandstones and carbonates: dependence on pore structure. Water Resour Res 48(8), DOI 10.1029/2011WR011712

Tanino Y, Blunt MJ (2013) Laboratory investigation of capillary trapping under mixed-wet conditions. Water Resour Res 49(7):4311-4319, DOI 10.1002 /wrcr.20344

Tanino Y, Akamairo B, Christensen M, Bowden SA (2015) Impact of displacement rate on waterflood oil recovery under mixed-wet conditions. In: Proc., International Symposium of the Society of Core Analysts, Society of Core Analysts, St. John's Newfoundland and Labrador, Canada, SCA-A031

Valvatne PH, Blunt MJ (2004) Predictive pore-scale modeling of twophase flow in mixed wet media. Water Resour Res 40(7):W07,406, DOI 10.1029/2003WR002627

Wood AR, Wilcox TC, MacDonald DG, Flynn JJ, Angert PF (1991) Determining effective residual oil saturation for mixed wettability reservoirs: Endicott Field, Alaska. In: Proc., SPE Annual Technical Conference and Exhibition, 6-9 Oct., Society of Petroleum Engineers, Dallas, Texas, SPE 22903, DOI 10.2118/22903MS

Wu Y, Shuler PJ, Blanco M, Tang Y, Goddard III WA (2008) An experimental study of wetting behavior and surfactant EOR in carbonates with model compounds. Soc Petrol Eng J 13(1):26-34, DOI 10.2118/99612-PA 
Yaralidarani M, Shahverdi H (2018) Co-estimation of saturation functions (kr and Pc) from unsteady-state core-flood experiment in tight carbonate rocks. J Petrol Explor Prod Technol 8(4):1559-1572, DOI 10.1007/s13202-018-0452-5 